\title{
CABEZALES LÍTICOS DEL HOLOCENO TARDÍO EN PATAGONIA MERIDIONAL: DISEÑOS Y ASIGNACIÓN FUNCIONAL
}

\author{
ANAHI BANEGAS*; JULIETA GÓMEZ OTERO**, \\ SOLEDAD GOYE*"* \& NORMA RATTO**"
}

\section{RESUMEN}

Desde el poblamiento temprano circa 11.000 AP hasta el período post contacto, en Patagonia Meridional se utilizaron armas con cabezales líticos que fueron variando en diseño y tamaño a través del tiempo. Con el objetivo de conocer las tecnologías de caza implementadas por los grupos cazadores recolectores locales, se presentan y discuten los resultados de la atribución funcional de 47 cabezales líticos del área, para la cual se aplicó una versión modificada del modelo de asignación funcional de Norma Ratto. Los resultados indican que en el Holoceno tardío se utilizaron distintos sistemas técnicos: armas de mano no arrojadizas, lanzas arrojadizas con propulsión manual y arcos y flechas. Los dos últimos sistemas habrían sido aplicados de manera simultánea en los últimos 900 años. Se observó el uso de cabezales característicos del Período IV para los tres tipos de arma. Esto sugiere mecanismos de mantenimiento y transmisión de un diseño exitoso que se fue adaptando formalmente a los distintos sistemas técnicos y estrategias de caza a través del tiempo.

PALABRAS CLAVE: cabezales líticos, Holoceno tardío, Patagonia meridional, diseños, funcionalidad.

\section{LATE HOLOCENE WEAPON LITHIC HEADS FROM SOUTH PATAGONIA: DESIGNS AND FUNCTION}

\footnotetext{
ABSTRACT

Since the early settlement circa 11.000 AP to the Historical Period, aboriginal hunter-gatherers from Southern Patagonia used different weapons with lithic heads which size and design changed through time. In this work we present and discuss the results of the functional attribution of 47 points of the area studied over the basis of a model proposed by Norma Ratto. The results indicate that different weapon systems were used in the late Holocene: thrusting spears, thrown spears, and bows and arrows. The

* Centro Nacional Patagónico - CONICET, Bvd. Brown 2915 (9120). banegas.anahi@yahoo.com.ar

* Centro Nacional Patagónico - CONICET, Bvd. Brown 2915 (9120) y UNPSJB. julietagomezotero@yahoo.com.ar

* Secretaría de Cultura del Chubut - Centro Nacional Patagónico-CONICET, Bvd. Brown 2915 (9120).msgoye@yahoo.com.ar

Museo Etnográfico, Fac. Filosofía y Letras (UBA). Moreno 350 (1091). Ciudad de Buenos Aires. norma_ratto@yahoo.com.ar
} 
last two systems have been implemented simultaneously in the last 900 years. The Period IV type point was used for the three kind of weapon. This suggests mechanisms of maintenance and transmission of a successful design that was formally adapting to the different technical systems and hunting strategies through time.

KEY WORDS: lithic points, Late Holocene, Southern Patagonia, designs, function.

\section{INTRODUCCIÓN}

Uno de los sectores más estudiados por la arqueología es el extremo meridional de Patagonia continental, particularmente el Campo Volcánico Pali-aike, que se extiende a lo largo de la frontera binacional entre Argentina y Chile (paralelo $52^{\circ}$ S). Las primeras investigaciones fueron llevadas a cabo en las cuevas Pali-aike y Fell por Junius Bird (1938), quien reconoció distintos estratos culturales y elaboró un modelo de periodización, pionero para la arqueología americana de entonces. Sobre la base de los rasgos de los conjuntos tecnológicos y arqueofaunísticos propuso la existencia de cinco períodos (Períodos I a V), que luego Willey (1971) denominó "Magallanes I a V". Dataciones radiocarbónicas posteriores evidenciaron una prolongada historia de ocupación humana que se habría iniciado hacia el 11.000 AP y perdurado hasta tiempos históricos recientes (Bird 1988; Emperaire et al. 1963; Sanguinetti \& Borrero 1977; Massone 1981; Ortiz Troncoso 1972).

Entre los rasgos de la tecnología que Bird $(1938,1988)$ consideró claves para justificar esta secuencia se encuentran las puntas o cabezales líticos bifaciales que durante muchos años se utilizaron como "fósiles guía" para atribuir identidad cultural a los contextos o estimar su cronología relativa. De esta manera, cada período estaba representado por un tipo de punta: el Período I (11.000-10.000 ${ }^{14} \mathrm{C}$ AP) por las llamadas "cola de pescado", de amplia distribución en los sitios más tempranos de Sudamérica (Castiñeira et al. 2009; Politis et al. 2009); el período II únicamente por puntas óseas de distintas formas y tamaños; el Período III (8000$6000 \mathrm{AP}$ ) por cabezales triangulares sin pedúnculo (aunque también por piezas pedunculadas de gran tamaño); el Período IV (4500-800 AP) por puntas medianas de limbo triangular, pedúnculo ancho y espeso y terminación tosca, que según Bird (1938) corresponderían a cuchillos o lanzas utilizadas por los antepasados de los tehuelches. Por último, el Período V (entre 900 AP y el contacto con los europeos) se distingue por cabezales líticos microlíticos de pedúnculo angosto, atribuidos por Bird (1938) a los grupos Ona o selk'nam de Tierra del Fuego, motivo por el cual frecuentemente se las llama "puntas Ona".

Este modelo de periodización estuvo en vigencia y sin cuestionamientos hasta 1980 , cuando comienzan a aplicarse nuevos abordajes teóricos. La primera revisión sobre la secuencia de Bird y su relación con la tipología de las puntas fue efectuada por Mauricio Massone (1981). Este autor no halló fundamentos para separar el Período V del IV: por una parte en el más tardío se había observado la perduración de rasgos tecnológicos propios del precedente; por otra, en sitios del estrecho de Magallanes se verificó la coexistencia de puntas de ambos períodos (Massone 1979). Sobre esta base propuso la existencia de una "Unidad Cultural Tardía", que habría comenzado circa 4500 años AP y perdurado hasta 250 AP (Massone 1981:112). Consideró además que las puntas microlíticas "tipo Ona" eran una adición tipológica a las variedades ya existentes, y coincidió con Bate (1978-79) en que su presencia se relacionaba con la introducción del arco y la flecha en el área. No obstante, dejó abierta la posibilidad que este tipo de arma se hubiera adoptado poco antes, ya que en contextos del período IV se registraron puntas de muy pequeño tamaño que podrían haber sido cabezales de flechas.

Poco tiempo después las investigaciones emprendidas por Gómez Otero (1987) en el alero Potrok-aike mostraron contemporaneidad entre las puntas del período IV y V. La autora propuso que el período $V$ fue en realidad una fase más moderna del IV y que las puntas microliticas se agregaron al bagaje tecnológico para cumplir una función específica que debía determinarse (Gómez Otero 1987:129). En un trabajo posterior consideró 
que estos cabezales habrían significado una evolución tecnológica en las estrategias de caza, ya que su pequeño tamaño permitiría abatir con mayor efectividad a los guanacos (Gómez Otero 1988:195). En consonancia con Massone (1981), sostuvo que las mismas se habían utilizado en arcos y flechas y que este tipo de armas ya habría comenzado a implementarse antes. En síntesis, tanto Massone como Gómez Otero privilegiaron el tamaño y no el diseño de las puntas para inferir la función de las mismas.

Sobre la base del uso de la analogía etnográfica con la arquería selk'nam, Prieto (1989-90) cuestionó la funcionalidad inferida por los autores arriba mencionados y planteó que las puntas "tipo Ona" halladas en el Alero Peggy Bird y en otros sitios del área no correspondían a herramientas de caza. Según testimonios directos de los misioneros Gusinde (1982) y Gallardo (1910), los arqueros selk'nam buscaban que los guanacos murieran desangrados. Para ello debían evitar que la flecha chocara con un hueso y se rompiera, perdiéndose así la presa. Por lo tanto era necesario que las puntas cumplieran con los siguientes requisitos: a) que el ápice asegurara la penetración; b) que el sector de las aletas fuera ancho -el largo no era tan importante-; c) que la guarnición de las plumas tuviera más amplitud que las aletas; y d) que la unión del pedúnculo con el astil ofreciera poca resistencia a la penetración. Además, la flecha debía ser disparada por detrás del animal para así penetrar las partes blandas y llegar a los órganos vitales en el momento del disparo. Prieto contrastó estas variables con diversas puntas del período $\mathrm{V}$ y observó que la mayoría no alcanzaba el ancho requerido entre aleta y aleta (más de $15 \mathrm{~mm}$ ). Esto lo llevó a hipotetizar que en realidad sirvieron como "ejercicio para niños o para algún otro uso desconocido" (Prieto 1989-90: 83-84).

Desde un enfoque diferente Ratto (1994) realizó el análisis de 27 puntas de proyectil de los sitios Potrok-aike $1(\mathrm{n}=11)$ y Juni-aike $1 \quad(\mathrm{n}=16)$ estudiados por Gómez Otero (1988, 1989-90). Para ello puso a prueba un modelo de su autoría que aborda la funcionalidad de los cabezales líticos como componentes de un sistema técnico o arma (Ratto 1993, 2003, 2012). A través del estudio de distintos atributos y el uso de métodos estadísticos, determinó que los cabezales analizados representaban tres tipos de armas: lanza arrojadiza con propulsión a mano, arma no arrojadiza de mano, y arco y flecha. De los tres sistemas técnicos, el más empleado en los sitios examinados fue el primero (76 \%), siguiéndole el arco y la flecha (19\%), mientras que sólo registró un caso de arma no arrojadiza de mano (Ratto 1994).

Recientemente, y mediante la aplicación de la morfometría geométrica y la estadística multivariada, Charlin y González-José analizaron 118 puntas pedunculadas con alto grado de integridad de los períodos IV y $\mathrm{V}$ provenientes de sitios del Holoceno tardío del extremo sur de Patagonia (Charlin \& González-José 2012; González-José \& Charlin 2012). Por una parte trataron de identificar los atributos morfológicos determinantes de la mayoría de la varianza en la muestra, así como verificar la relación entre estos dos tipos de puntas y un sistema bimodular integrado por el limbo y el pedúnculo (GonzálezJosé \& Charlin 2012). El estudio permitió discriminar tres tipos de puntas (I, II y III) vinculados a distintas armas: a) las T I son similares a las Bird V y fueron atribuidas a flecha; b) las T II, semejantes a las Bird IV, corresponderían a puntas de lanza, y c) las T III están representadas por cuatro ejemplares asignados a armas de mano. Las lanzas arrojadizas (inclusive los ejemplares reactivados o reafilados) y las flechas derivarían de un sistema formado por dos componentes estrechamente relacionados: el ápice y el resto del proyectil. Por el contrario, las puntas de arma no arrojadizas se vincularían con un sistema bimodular conformado por el limbo y el pedúnculo. Los autores además determinaron que la reducción lítica tuvo más efecto en la forma y el limbo que en el tamaño y el pedúnculo (Charlin \& González-José 2012), y que las diferencias entre ambos sistemas se mantuvieron -probablemente por demandas funcionales- a pesar de las modificaciones en tamaño y forma producidas por los sucesivos ciclos de uso, desgaste y reutilización.

A los efectos de profundizar la discusión sobre los tipos de arma utilizados por los grupos cazadores-recolectores de Patagonia meridional durante el Holoceno tardío, en este trabajo se presentan nuevos resultados de la aplicación del modelo de asignación funcional de Ratto (1994, 2003, 2012) a 47 puntas líticas de cuatro localidades arqueológicas de la cuenca media y 
media-superior del río Gallegos. Los principales objetivos fueron: determinar la distribución espacial y temporal de las distintas variedades de cabezales, identificar continuidades y discontinuidades en los diseños, y explorar las decisiones tecnológicas y su relación con los factores ecológicos y sociales que habrían intervenido en la adopción y selección de las estrategias de caza.

\section{EL MODELO DE ASIGNACIÓN FUNCIONAL (MAF)}

La caza es un comportamiento complejo que se organiza básicamente sobre tres ejes: el uso de un espacio, la dinámica social y la demografía de los grupos. De acuerdo con el MAF, los cabezales líticos no son "fósiles guía" de adscripción cultural y cronológica, sino el resultado de distintas estrategias en relación con la tecnología de caza, los recursos del ambiente, la topografía del lugar y la etología de las presas (Ratto 1991; 2003; 2012, entre otros). El estudio de estos factores, sumado al de las variables morfométricas y el diseño de las puntas, permite reconstruir la organización tecnológica de la caza (Nelson 1991).

Para la elaboración de su modelo Ratto (2003) tomó en cuenta las tendencias observadas por Churchill (1993) respecto del uso de los sistemas técnicos de caza entre grupos cazadoresrecolectores actuales de distintas latitudes $y$ ambientes. Este autor registró que las armas no arrojadizas y/o empuñadas en mano están asociadas estadísticamente con la captura de presas terrestres de gran porte $(>100 \mathrm{~kg}$ promedio) en situación de desventaja del animal o en la caza al acecho. La topografía del ambiente y el uso de perros, caballos, botes u otro tipo de tecnologías complementan y aseguran mayor eficacia. En cuanto a las lanzas arrojadizas, si bien las referencias etnográficas al respecto no son abundantes, se pudo constatar su utilización en presas de gran porte y su aplicación en variadas técnicas de caza y en distintas situaciones. Por último, Churchill (1993) comprobó la superior eficiencia del arco y la flecha ya que permiten: (a) capturar un rango más amplio (23 a $230 \mathrm{~kg}$ ) de tamaños de presa; (b) seleccionar y adecuar la técnica de caza según la etología de los distintos animales y (c) cazar en solitario y sin ayuda de complementos.

Otro aspecto relevante del modelo es el diseño, que se construye sobre la base de las propiedades físico-mecánicas de las materias primas (rocas y maderas), la mecánica de funcionamiento de los sistemas de caza y la resistencia ofrecida por el cuero y la masa muscular del animal. Particularmente, la mecánica de funcionamiento de los equipos de caza y las propiedades físicomecánicas de las materias primas vegetales y líticas definen las variables para la asignación funcional de las puntas. Tales aspectos se materializan en atributos morfométricos e índices y/o en las propiedades estructurales de las materias primas empleadas en la manufactura (Tabla 1).

Finalmente, es importante destacar que la aplicación del MAF se dificulta cuando los cabezales presentan alta tasa de fractura, mantenimiento o transformación. Por lo tanto, para el caso que nos ocupa se aplicó una estrategia complementaria que articula los criterios de asignación funcional del MAF con análisis estadísticos multivariados (veáse más adelante "Materiales y métodos").

\section{Las variables ambientales}

del área en función del modelo

El área de estudio se encuentra en la cuenca media-superior del río Gallegos (Figura 1), entre $71^{\circ} 30^{-} \mathrm{S}$ y $70^{\circ} 16^{-} \mathrm{S}$ y $52^{\circ} \mathrm{O}$ y $51^{\circ} 42^{-} \mathrm{O}$, que corresponde al sector septentrional del llamado "Campo Volcánico Pali-Aike" -en adelante CVPA(Skewes 1978). El paisaje se caracteriza por mesetas escalonadas que decrecen en altitud de oeste a este (400 m a 100 m s.n.m.), geoformas volcánicas, cañadones hoy secos, depresiones que a veces se hallan por debajo del nivel del mar y amplios valles -como el del río Gallegosenmarcado por sus propias terrazas. En la región abundan afloramientos rocosos que ofrecen aleros y cuevas, parapetos naturales y soporte para manifestaciones rupestres.

Estudios de disponibilidad de rocas realizados en el CVPA indican que las de buena calidad para la talla se obtienen en depósitos secundarios de origen glacifluvial, mayormente concentrados en las costas de los cursos de agua y lagunas (Charlin 2009, Charlin et al. 2010). Nódulos de 
Tabla 1. Modelo de asignación funcional adaptado de Ratto (2003, 2012).

\begin{tabular}{|c|c|c|c|c|}
\hline \multicolumn{2}{|c|}{ Sistemas técnicos } & \multirow{2}{*}{$\begin{array}{c}\text { Con almacenamiento de } \\
\text { energía }\end{array}$} & \multicolumn{2}{|c|}{ Sin almacenamiento de energía } \\
\hline Variables & Atributos & & Lanza & Arma de mano \\
\hline $\begin{array}{l}\text { Superficie de } \\
\text { refuerzo }\end{array}$ & $\begin{array}{l}\text { - Cociente entre el } \\
\text { espesor máximo de } \\
\text { la pieza y el ancho en } \\
\text { ese mismo punto. }\end{array}$ & $\begin{array}{c}\text { - Bajo índice de módulo } \\
\text { de refuerzo. } \\
\text { - Baja o media } \\
\text { tenacidad de la roca. } \\
\text { - Bajo riesgo de fractura } \\
\text { ápice }\end{array}$ & $\begin{array}{c}\text { - Medio, alto o muy alto índice } \\
\text { de módulo de refuerzo - A } \\
\text { menor tenacidad de la roca } \\
\text { mayor módulo de refuerzo. } \\
\text { - Tenacidad elevadas para } \\
\text { disminuir la superficie de } \\
\text { refuerzo. } \\
\text { - Alto riesgo de fractura } \\
\text { (aletas, pedúnculos y limbos). }\end{array}$ & $\begin{array}{c}\text { - Bajo índice de módulo } \\
\text { de refuerzo. } \\
\text { - Baja o media tenacidad } \\
\text { de la roca. } \\
\text { - Moderado riesgo de } \\
\text { fractura. }\end{array}$ \\
\hline Aerodinámica & $\begin{array}{l}\text { - Sección transversal } \\
\text { de la pieza. } \\
\text { - Forma del contorno } \\
\text { del limbo. } \\
\text { - Largo y ancho del } \\
\text { limbo. }\end{array}$ & $\begin{array}{l}\text { - Perfecta o normal. } \\
\text { - A mayor superficie de } \\
\text { contacto se requiere de } \\
\text { mayor aerodinámica } \\
\text { general. }\end{array}$ & $\begin{array}{c}\text { - Imperfecta - alta superficie } \\
\text { de contacto-. } \\
\text { - No aerodinámica -baja } \\
\text { superficie de contacto. }\end{array}$ & No aplica \\
\hline Enmangue & $\begin{array}{c}\text { - Ancho y espesor del } \\
\text { pedúnculo o base. } \\
\text { - Largo del } \\
\text { pedúnculo. }\end{array}$ & $\leq 10 \mathrm{~mm}$ & $>10 \mathrm{~mm}$ & $>10 \mathrm{~mm}$ \\
\hline Penetración & $\begin{array}{l}\text { - Ángulo vista plana. } \\
\text { - Sección del ápice. }\end{array}$ & $\begin{array}{c}\text { - Sección ápice } \leq \\
1 \mathrm{~mm}^{2} . \\
\text { - Angulo vista plana } \leq \\
45^{\circ} .\end{array}$ & $\begin{array}{c}\text { - Sección ápice }>1 \mathrm{~mm}^{2} \leq \\
1,50 \mathrm{~mm}^{2} . \\
\text { - Ángulo vista plana }>45^{\circ} \text {. }\end{array}$ & $\begin{array}{c}\text { - Sección ápice }>1 \mathrm{~mm}^{2} \\
\leq 1,50 \mathrm{~mm}^{2} \\
\text { - Angulo vista plana } \\
>45^{\circ}\end{array}$ \\
\hline
\end{tabular}

rocas oscuras de grano fino (basaltos, andesitas, dacitas, ftanitas, lutitas, entre otras) ${ }^{1}$ se registraron sobre cotas altas y cuerpos lagunares del valle del río Gallegos, en el interfluvio Gallegos- Chico y cerca del cañadón Gap en la costa marina. Los rodados de mayores dimensiones y mejor calidad se encuentran en la Laguna Potrok-aike y en la estancia Las Buitreras; Charlin \& Pallo (2013) las denominan "tipo Potrok-aike", registrando su distribución no más allá de los $35 \mathrm{~km}$ del interfluvio. También se registraron nódulos grandes de dacitas claras pero solamente el $3 \%$ es apto para la talla. Las fuentes de otras materias primas, como la calcedonia y las obsidianas de distintas variedades, prácticamente no han sido identificadas en el área, excepto guijarros aislados de pequeño tamaño (Charlin 2009). En relación con las calcedonias, recientemente se dio a conocer su presencia en la laguna Potrok-aike y en Carolina 1, si bien en una muy baja frecuencia (Charlin \& Pallo 2013).
Con respecto a las maderas para las armas, el área de estudio comprende dos comunidades vegetales: el ecotono bosque-estepa desde la laguna Cóndor hacia el oeste y la Estepa Patagónica al este de la laguna. En el sector ecotonal crecen ejemplares aislados y de menor porte del género Nothofagus sp., característico del bosque andino-patagónico. La estepa está dominada por gramíneas duras y arbustos rastreros, siendo el arbusto de mayor tamaño el calafate, representado por dos especies: Berberis buxifolia y Berberis ilicifolia (Pisano 1977). Según fuentes etnográficas estas maderas eran utilizadas por los selk'nam de fines del siglo XIX y principios del XX para la confección de arcos y flechas (Chapman 1986; Prieto Iglesias 1994; Ratto 2003, Carusso Fermé et al. 2011). Los arcos se fabricaban con ramas de Nothofagus (especialmente $N$. antarctica o ñire y $\mathrm{N}$. betuloides o lenga) y también se usaba leñadura o maitén (Maytenus magellanica), que es una 
especie arbustiva. Para los astiles aprovechaban casi cualquier rama de árboles pequeños $y$ de arbustos, en especial la chaura o murta (Pernettya mucronata), la leñadura, la mata negra (Chiliotrichium diffusum) y las dos especies de Berberis. Esto fue en parte confirmado por análisis arqueobotánicos de astiles y arcos etnográficos fueguinos: los primeros estaban confeccionados con madera del género Berberis (Ratto \& Marconetto 2012); los segundos con Nothofagus betuloides (Caruso Fermé et al. 2011).

En cuanto a la etología de las presas, si bien los recursos faunísticos locales de mayor tamaño y aporte nutricional son el guanaco (Lama guanicoe) y el choique (Pterocnemia pennata), en este trabajo se considerará solamente al guanaco por su relevancia económica para los cazadores patagónicos desde los inicios del poblamiento. Además, su representación es predominante en los sitios aquí tratados. Este animal es de hábitos gregarios y de distribución pareja y dispersa; su área de forrajeo es reducida, no alejándose más de un kilómetro y medio de sus lugares de descanso nocturno (Franklin 1983; Raedecke 1978). Su estructura social está organizada en tres tipos básicos de agrupamiento: grupos familiares, grupos de machos y machos solitarios (Puig \& Videla 1995). Según un estudio de Saba (1987) los grupos familiares del guanaco -los más territoriales y predecibles- tienden a localizarse en los valles próximos a adecuadas vías de escape (escoriales o serranías volcánicas), sobre todo en el período reproductivo.

En síntesis, la estructura ambiental del área de estudio ofrece rocas y maderas aptas para la confección de armas, abundante disponibilidad de una presa terrestre de gran porte y de localización predecible como el guanaco, y una topografía variada donde es posible aplicar distintas tácticas y técnicas de caza.

\section{MATERIALES Y MÉTODOS}

El conjunto está compuesto por 47 puntas (46 pedunculadas y una apedunculada), halladas en contextos de superficie y/o estratificados de

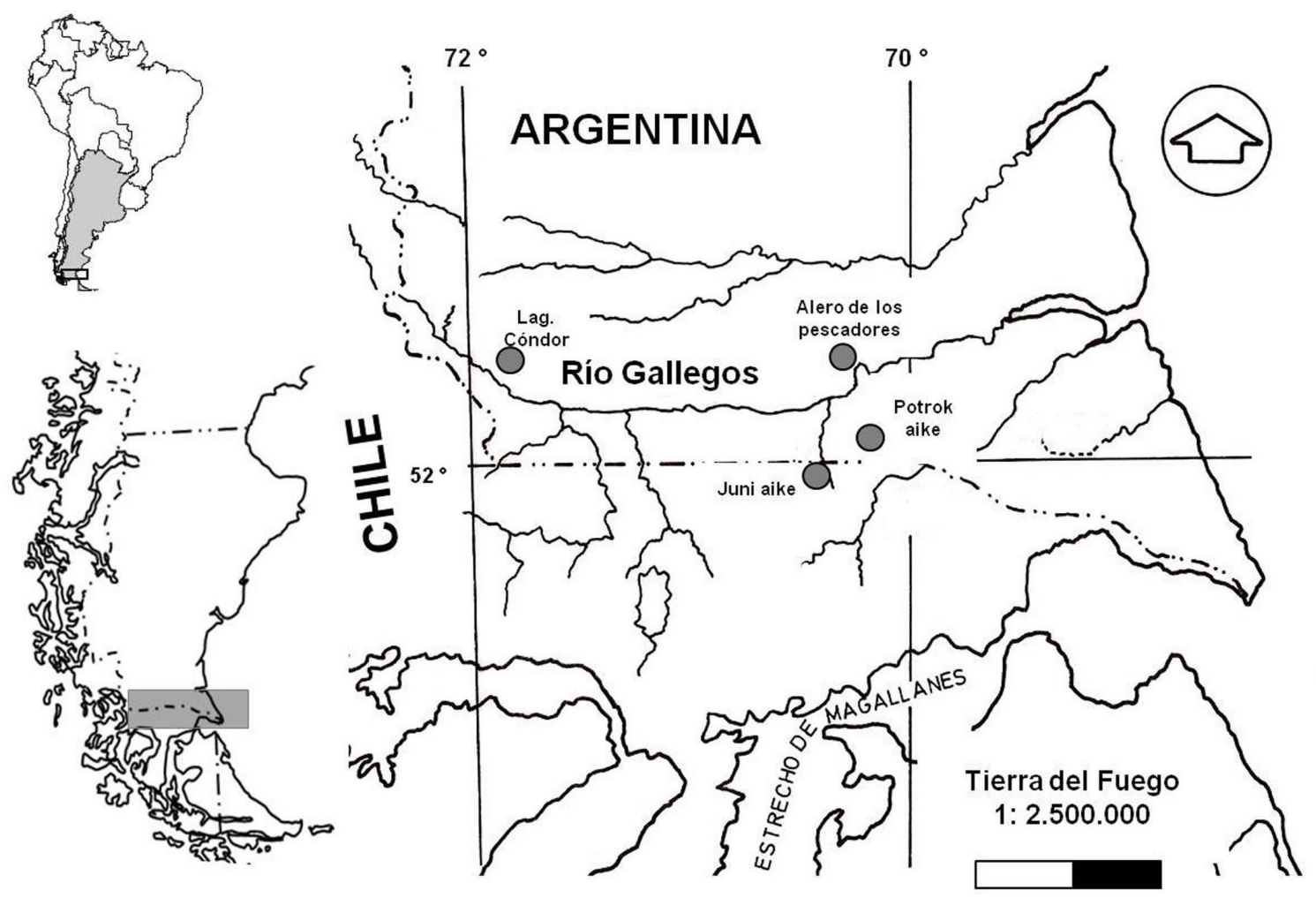

Fig. 1. El área de estudio. 
cuatro localidades arqueológicas: Laguna Potrokaike $(\mathrm{n}=27)$, Colección Estévez-CMRG $(\mathrm{n}=15)^{2}$, alero Juni-aike $1(n=3)$ y Laguna Cóndor $(n=1)$ (Tabla 2). Los ejemplares de Potrok -aike y dos de Juni-aike 1 (B44-21 y B236-32) habian sido previamente estudiados por Ratto (1991). La Colección Estévez incluye puntas recolectadas por el Sr. Bartolomé Estévez en la cuenca media del río Gallegos (CMRG), sin referencia a su localización en superficie o en estratigrafía. Con respecto a la antigüedad, solamente se cuenta con dataciones para los aleros Potrok-aike 1 y Juni-aike 1 (Gómez Otero 1991), que indican ocupaciones entre el Holoceno tardío (circa 2000-2500 AP) y tiempos postcontacto (Tabla 2).

Para el análisis se tuvieron en cuenta los atributos de diseño de los cabezales propuestos por el MAF (Tabla 1). Sin embargo, debido al alto porcentaje de piezas fracturadas y/o la baja representación de diseños básicos se decidió realizar el análisis en tres pasos. En primer lugar se aplicaron directamente todos los criterios del MAF a aquellos ejemplares enteros y/o con fracturas mínimas que permitiesen proyectar o reconstruir su forma original. Luego, para clasificar las piezas con bajo grado de integridad -como los pedúnculos con o sin bases de limbos- se tomaron como patrón las características diagnósticas del diseño de los ejemplares ya atribuidos en la primera instancia. La corrección de los grupos (sistemas técnicos) fue lograda a partir de las variables del área del enmangue que son las más representadas en las piezas fracturadas. Por lo tanto se consideraron las dimensiones del pedúnculo, el espesor del limbo, el módulo de refuerzo (MODUREFU) y/o la tenacidad de la roca. Por último, para corregir la asignación de los sistemas técnicos se realizó un Análisis Discriminante mediante el cálculo de la distancia de Mahalanobis. Esto se completó con un procedimiento ANOVA que permite reconocer

Tabla 2. Localidades y sitios arqueológicos donde fueron recuperados los cabezales analizados.

\begin{tabular}{|c|c|c|c|c|c|c|c|c|}
\hline Localidad & Sitio & $\begin{array}{c}\text { Tipo } \\
\text { de sitio }\end{array}$ & $\begin{array}{l}\text { Profun- } \\
\text { didad }\end{array}$ & Cuad. & $\mathrm{N}$ & $\begin{array}{c}\text { Edad } \\
{ }^{14} \mathrm{C} \mathrm{AP}\end{array}$ & $\begin{array}{c}\text { Edad } \\
\text { Corregida } \\
\text { (1 sigma) }\end{array}$ & Referencias \\
\hline \multirow{7}{*}{ 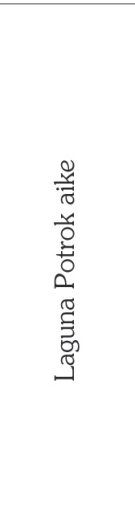 } & $\begin{array}{l}\text { Márgenes } \\
\text { laguna }\end{array}$ & Sup. & - & - & 9 & - & - & $\begin{array}{l}\text { Gómez Otero } \\
\text { (1987) }\end{array}$ \\
\hline & \multirow{5}{*}{$\begin{array}{l}\text { Alero Potrok- } \\
\text { aike } 1\end{array}$} & \multirow{5}{*}{ Estratif. } & $-39 \mathrm{~cm}$ & $\mathrm{C}$ & 15 & $360 \pm 50$ & 1500-1597 DC & (LP- 2639) \\
\hline & & & $-40 \mathrm{~cm}$ & B & & $740 \pm 180$ & 1152-1406 DC & $\begin{array}{l}\text { Gómez Otero } \\
(1987,1988)\end{array}$ \\
\hline & & & $-1,03 \mathrm{~cm}$ & $\mathrm{C}$ & & $1280 \pm 40$ & $770-873 \mathrm{DC}$ & (LP- 2567) \\
\hline & & & $-1,28 \mathrm{~cm}$ & $\mathrm{C}$ & & $2120 \pm 70$ & $175 \mathrm{AC}-5 \mathrm{DC}$ & (LP- 2569) \\
\hline & & & $-1,48 \mathrm{~cm}$ & C & & $2320 \pm 95$ & $524-347$ AC & (LP-482) \\
\hline & Reparo & Estratif. & - & - & 3 & - & - & $\begin{array}{l}\text { Gómez Otero } \\
\text { (1987) }\end{array}$ \\
\hline$\dot{0} \underset{0}{\stackrel{N}{\infty}}$ & $\begin{array}{c}\text { Cuenca } \\
\text { media del río } \\
\text { Gallegos }\end{array}$ & $\begin{array}{c}\text { Sin } \\
\text { datos }\end{array}$ & - & - & 15 & - & - & $\begin{array}{l}\text { Sin datos } \\
\text { contextuales }\end{array}$ \\
\hline 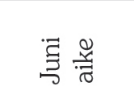 & $\begin{array}{l}\text { Alero Juni- } \\
\text { aike } 1\end{array}$ & Estratif. & $-94 \mathrm{~cm}$ & B & 3 & $850 \pm 40$ & 1158-1228 DC & $\begin{array}{l}\text { Gómez Otero } \\
(1989-90)\end{array}$ \\
\hline 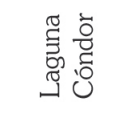 & $\begin{array}{l}\text { Laguna } \\
\text { Cóndor }\end{array}$ & Sup. & - & - & 1 & - & - & $\begin{array}{l}\text { Gómez Otero } \\
\text { (1991) }\end{array}$ \\
\hline
\end{tabular}

2 El Sr. Bartolomé Estévez, fue uno de los colaboradores del Padre Manual J. Molina en las excavaciones del sitio Alero de los Pescadores (Molina 1969-71). 
igualdad o diferencias en las medias de las variables métricas en función de los sistemas técnicos asignados. En todos los tratamientos estadísticos se utilizó el programa SPSS 19.

Para la diferenciación entre tipos de diseño se recurrió a la caracterización propuesta por Aschero et al. (2011) y Martínez (2003). En este sentido, un diseño "básico" es el que conserva su morfología original; un diseño "mantenido" es el producto de la reactivación del filo para seguir desempeñando la misma función, mientras que un diseño "transformado" es el que sufre modificaciones morfológicas para cumplir alguna otra función. Por último, la categoría "descartados" incluye ejemplares fracturados que no evidencian actividades de transformación ni de mantenimiento.

Para las piezas con un alto grado de integridad (más del 75 \%) se calcularon los índices de Reavivamiento y de Robustez empleados por Cardillo (2005), quien los toma de Iriarte (1995) y Scheinsohn (1997) respectivamente. Estos índices son útiles para detectar cambios alométricos en el diseño vinculados con procesos de mantenimiento. El de Reavivamiento se obtiene de la división del largo por el espesor máximo, ya que se considera que este último es poco sensible a la reactivación. La función muestra que el espesor de las puntas aumenta a medida que disminuye su largo. Por lo tanto, se espera que la correlación entre el Índice de Reavivamiento y el largo sea baja (positiva o negativa). El índice de Robustez se calcula a partir de la multiplicación del ancho máximo por el espesor máximo sobre el largo total; en consecuencia, los valores más altos corresponden a formas proporcionalmente más robustas. También es esperable que esto ocurra en el caso de reducción proporcional del ancho y el largo durante la reactivación de los limbos, lo cual en numerosos casos deriva en la conformación de "subgrupos morfológicos" (Scheinsohn 1997).

En cuanto a la determinación petrográfica y la tenacidad de las rocas, por una parte se tuvo en cuenta el estudio de secciones delgadas y ensayos mecánicos de Ratto \& Nestiero (1994), así como también una nueva clasificación petrográfica macroscópica efectuada por el vulcanólogo Miguel Haller (com. pers. 2011). Se determinó el grupo o familia de roca (volcánica, metamórfica o sedimentaria); se describió la textura, el tamaño de los fenocristales y la determinación relativa de su abundancia. Sobre esta base se efectuaron las siguientes asignaciones: basalto, andesita-basalto, andesita, sílice, calcedonia y obsidiana.

\section{RESULTADOS}

De los 47 cabezales estudiados, los ejemplares con alto grado de integridad $(n=31)$ pudieron ser asignados directamente mediante la aplicación de los criterios del MAF (Figura 2 y Tabla 3). Para la asignación de los dieciséis restantes (que presentaban bajo grado de integridad), se usaron los métodos complementarios lográndose la clasificación de quince ejemplares. Sólo quedó sin determinar un fragmento de pedúnculo de calcedonia del alero Potrok-aike 1 (PA-A1 171/36) (Figura 2 y Tablas 3 y 4). Se pudo reconocer la representación de los tres sistemas de armas: 19 lanzas (41 \%), 18 armas de mano (39\%) y 9 flechas (20\%). Cabe señalar que dos piezas de Juni-aike 1 que en este trabajo fueron atribuidas a flecha (JA1 B 44 y JA1 B 236) habían sido asignadas previamente a lanzas (Ratto 1991: Tabla 3).

De la muestra total, solo tres cabezales están enteros; los 44 restantes (incluida la apedunculada) presentan algún tipo de fractura. Se observaron variaciones en la posición de las fracturas según el sistema de arma. Entre las lanzas predominan los ejemplares con fractura múltiples y además son las únicas que muestran aletas fracturadas. En las armas de mano las fracturas se concentran en el limbo superior, mientras que la fractura en el ápice sólo se identificó entre las flechas (Tabla 5). Es importante destacar que las fracturas en la raíz del pedúnculo aparecen en los tres sistemas técnicos, lo que señala su independencia respecto del tipo de arma. La proporción de pedúnculos fragmentados por arma es relativamente similar: $23 \%$ en las armas de mano, $16 \%$ en las lanzas y $22 \%$ en las flechas.

Las variables métricas también muestran diferencias según los sistemas de arma aunque en los ejemplares fracturados no pudieron ser medidas en su totalidad (Tabla 6):

a) El largo total real y /o inferido en 32 puntas fue: armas de mano $(78,69$ a $43,87 \mathrm{~mm})$, lanzas $(50,51$ a $31,10 \mathrm{~mm})$ y 


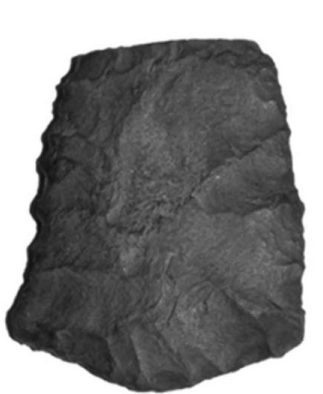

LPA 31-27

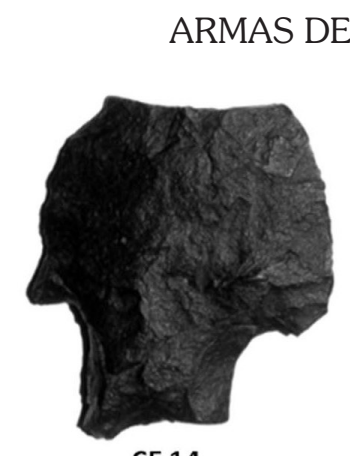

CE 14

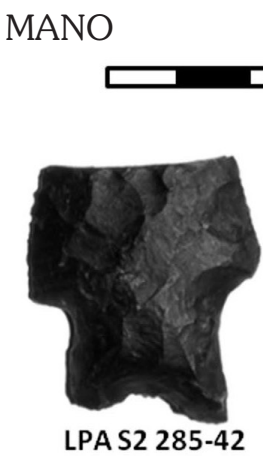

LPA S2 285-42

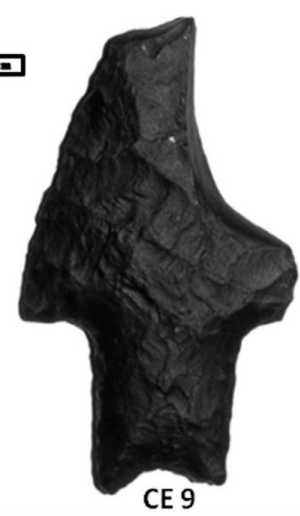

LANZAS

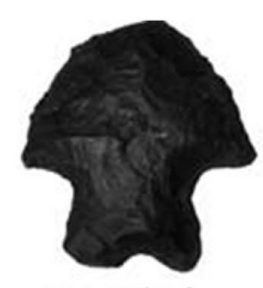

AP 1 A107-8

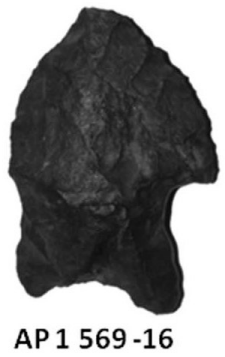

AP $1569-16$
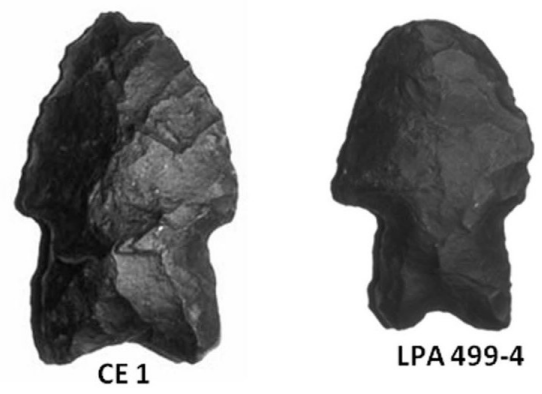

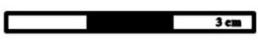

FLECHAS

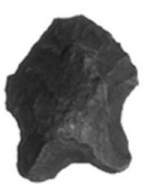

LPA 7

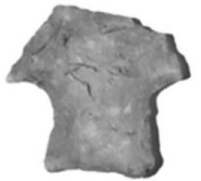

AP 1 138-23

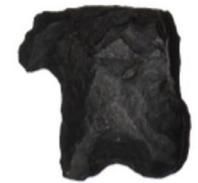

AP 1 IIIS-34

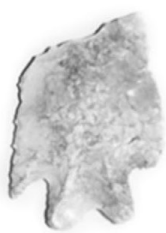

LPA 5

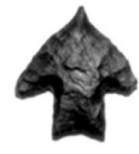

LC 19

Fig. 2. Cabezales líticos y sistemas de armas.

flechas (37,92 a 15,76 mm). Estas diferencias tiene significación estadística a nivel de 0,05 mediante el cálculo de ANOVA ( $\mathrm{F}=25,772$; p: 0,0003).

b) Los espesores máximos de 37 cabezales muestran valores similares entre las armas de mano (5,5 a 9,04 $\mathrm{mm}$ ) y las lanzas (5,72 a 9,34 mm), mientras que las flechas son bastante más delgadas (2,5 a 5,3 mm). El ANOVA da cuenta de diferencias en el sistema técnico en función de dicha variable $(\mathrm{F}=$ $13,775, p=0,0004)$. Indistintamente del tipo de arma, el espesor máximo se registró en el tercio inferior de las piezas: base del limbo o raíz del pedúnculo.

c) Respecto de las dimensiones en la zona de enmangue se reconocieron diferencias en el ancho máximo en 35 casos: armas de mano (24,60 a 44,17 mm), lanzas $(22,60$ a $33,60 \mathrm{~mm})$ y flechas $(12,84$ a 22,87 $\mathrm{mm})$. El ANOVA también muestra diferencias estadísticamente significativas para esta variable $(\mathrm{F}=25,186 ; \mathrm{p}=0,0002)$.

Con relación a las materias primas, las armas 
Tabla 3. Resultados de la aplicación del MAF a la muestra analizada.

\begin{tabular}{|c|c|c|c|c|c|c|c|c|c|c|c|c|}
\hline Sitio & ID & Sector & Prof. & $\begin{array}{l}\text { Asig. } \\
\text { Func }\end{array}$ & Diseño & Roca & Tenac. & Aerod & M.Ref. & Enmang. & S.A & A.V.P \\
\hline \multirow{15}{*}{ 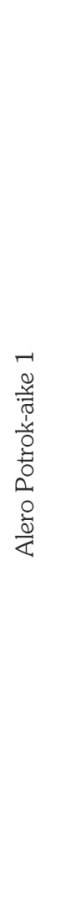 } & IIIS-34 & A & -20 & $\mathrm{~L}$ & $\mathrm{~T}$ & And-Ba & media & indet & medio & $>10 \mathrm{~mm}$ & sd & sd \\
\hline & S16-20 & Sondeo & -35 & $\mathrm{~F}$ & $\mathrm{D}$ & And-Ba & media & normal & bajo & $<10 \mathrm{~mm}$ & $<1 \mathrm{~mm}$ & $>45^{\circ}$ \\
\hline & B107-22 & $\mathrm{C}$ & -57 & $\mathrm{~L}$ & $\mathrm{~T}$ & And-Ba & media & indet & medio & $>10 \mathrm{~mm}$ & sd & sd \\
\hline & A107-8 & C & -57 & $\mathrm{~L}$ & M & And-Ba & media & imperf. & medio & $>10 \mathrm{~mm}$ & sd & $>45^{\circ}$ \\
\hline & $188-37$ & C & -61 & $\mathrm{~L}$ & I & And-Ba & media & indet & medio & $<10 \mathrm{~mm}$ & sd & sd \\
\hline & $138-23$ & C & -64 & $\mathrm{~F}$ & $\mathrm{~T}$ & Calc $^{*}$ & baja & perf. & bajo & $>10 \mathrm{~mm}$ & sd & $>45^{\circ}$ \\
\hline & $\begin{array}{c}293- \\
47 / 52\end{array}$ & C & -67 & $\mathrm{~F}$ & I & Obsid & baja & indet & sd & $<10 \mathrm{~mm}$ & sd & sd \\
\hline & A445-35 & C & -74 & $\mathrm{~L}$ & $\mathrm{D}$ & And-Ba & media & imperf. & medio & $>10 \mathrm{~mm}$ & sd & $>45^{\circ}$ \\
\hline & $27 / 44$ & Sondeo & -74 & $\mathrm{~L}$ & M & Calc $^{*}$ & media & imperf. & medio & $>10 \mathrm{~mm}$ & $<1 \mathrm{~mm}$ & $>45^{\circ}$ \\
\hline & $\begin{array}{c}30- \\
45 / 50\end{array}$ & Sondeo & -74 & $\mathrm{~L}$ & $\mathrm{~T}$ & $\mathrm{Ba}$ & media & imperf. & medio & $>10 \mathrm{~mm}$ & sd & sd \\
\hline & 494-49 & C & -76 & $\mathrm{~L}$ & B & And-Ba & media & imperf. & medio & $>10 \mathrm{~mm}$ & $\begin{array}{c}1 \text { a } 1,5 \\
\mathrm{~mm}\end{array}$ & $>45^{\circ}$ \\
\hline & 571-18 & C & -80 & $\mathrm{~L}$ & $\mathrm{~T}$ & And-Ba & media & indet & medio & $>10 \mathrm{~mm}$ & sd & sd \\
\hline & 569-16 & $\mathrm{C}$ & -82 & $\mathrm{~L}$ & M & And-Ba & media & imperf. & medio & $>10 \mathrm{~mm}$ & sd & $>45^{\circ}$ \\
\hline & B445-48 & C & -97 & $\mathrm{~L}$ & I & And-Ba & baja & indet & sd & $>10 \mathrm{~mm}$ & sd & sd \\
\hline & $572-11$ & Sin prof. & sd & $\mathrm{L}$ & B & And-Ba & media & indet & medio & $>10 \mathrm{~mm}$ & sd & sd \\
\hline \multirow{3}{*}{ 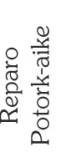 } & $14-40$ & Sondeo & -60 & AM & I & And-Ba & media & indet & sd & $>10 \mathrm{~mm}$ & sd & sd \\
\hline & $\begin{array}{c}15 / 13- \\
51 \\
\end{array}$ & Sondeo & -65 & $\mathrm{~L}$ & I & $\mathrm{Ba}$ & media & indet & sd & $>10 \mathrm{~mm}$ & sd & sd \\
\hline & $12 \quad 24$ & Sondeo & -70 & $\mathrm{AM}$ & I & Calc $^{*}$ & baja & indet & sd & $>10 \mathrm{~mm}$ & sd & sd \\
\hline \multirow{9}{*}{ 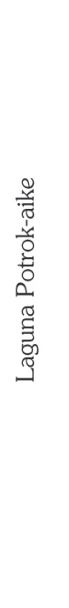 } & $285-42$ & $\mathrm{~S} 2$ & Sup. & AM & $\mathrm{D}$ & $\mathrm{Ba}$ & baja & no aéreo & bajo & $>10 \mathrm{~mm}$ & sd & sd \\
\hline & 7 & $\mathrm{~S} 2$ & Sup. & F & M & $\mathrm{Ba}$ & media & normal & bajo & $>10 \mathrm{~mm}$ & $<1 \mathrm{~mm}$ & sd \\
\hline & $500 / 13$ & S4 & Sup. & AM & $M$ & Sil & media & no aéreo & bajo & $>10 \mathrm{~mm}$ & $\begin{array}{c}1 \mathrm{a} 1,5 \\
\mathrm{~mm}\end{array}$ & $>45^{\circ}$ \\
\hline & $501 / 12$ & Sup. & Sup. & $\mathrm{L}$ & $M$ & $\mathrm{Ba}$ & media & imperf. & medio & $>10 \mathrm{~mm}$ & sd & $>45^{\circ}$ \\
\hline & $31 / 27$ & S3 & Sup. & AM & $\mathrm{T}$ & $\mathrm{Ba}$ & media & no aéreo & muy bajo & sd & sd & sd \\
\hline & $65 / 30$ & $\mathrm{~S} 1$ & Sup. & AM & $\mathrm{D}$ & $\mathrm{Ba}$ & media & normal & bajo & $>10 \mathrm{~mm}$ & $\begin{array}{c}1 \text { a } 1,5 \\
\mathrm{~mm}\end{array}$ & $>45^{\circ}$ \\
\hline & 10 & S5 & Sup. & AM & $\mathrm{T}$ & $\mathrm{Ba}$ & media & no aéreo & bajo & $>10 \mathrm{~mm}$ & sd & sd \\
\hline & $499 / 4$ & Sup. & Sup. & $\mathrm{L}$ & $\mathrm{T}$ & $\mathrm{Ba}$ & media & imperf. & medio & $>10 \mathrm{~mm}$ & sd & sd \\
\hline & 41 & Prosp. & nc & $\mathrm{F}$ & $\mathrm{D}$ & Sil & baja & perf. & bajo & $<10 \mathrm{~mm}$ & $\mathrm{sd}$ & $\mathrm{Sd}$ \\
\hline
\end{tabular}

* En Ratto (1991) se las clasificó como ftanita.

Referencias: A.Func: Asignación funcional; Enmang: enmangue; M.Ref: Módulo de refuerzo; S.A: sección ápice; A.V.P: ángulo vista plana; L: Lanza; AM: arma de mano; F: flecha; T: transformado; M: mantenido; B: básico; D: descartado; I: indeterminado; And-Ba: andesita - basalto; Ba: basalto; And: andesita; Calc: calcedonia; Obsid: obsidiana; Sil: sílice; perf: perfecta; imp: imperfecta; sd: sin dato. 


\begin{tabular}{|c|c|c|c|c|c|c|c|c|c|c|c|c|}
\hline Sitio & ID & Sector & Prof. & $\begin{array}{l}\text { Asig. } \\
\text { Func }\end{array}$ & Diseño & Roca & Tenac. & Aerod & M.Ref. & Enmang. & S.A & A.V.P \\
\hline & 1 & Sup. & Sup. & $\mathrm{L}$ & $\mathrm{T}$ & $\mathrm{Ba}$ & media & imperf. & medio & $>10 \mathrm{~mm}$ & sd & $>45^{\circ}$ \\
\hline & 2 & Sup. & Sup. & $\mathrm{L}$ & $\mathrm{T}$ & $\mathrm{Ba}$ & media & imperf. & medio & $>10 \mathrm{~mm}$ & sd & $\mathrm{sd}$ \\
\hline & 3 & C.E & Sup. & $\mathrm{L}$ & M & $\mathrm{Ba}$ & media & imperf. & medio & $>10 \mathrm{~mm}$ & sd & sd \\
\hline & 6 & C.E & Sup. & AM & $\mathrm{T}$ & $\mathrm{Ba}$ & media & imperf. & bajo & $>10 \mathrm{~mm}$ & $\mathrm{sd}$ & $\mathrm{sd}$ \\
\hline \multirow{11}{*}{ 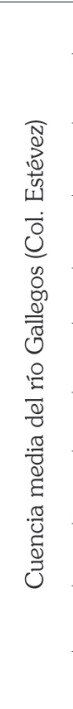 } & 9 & CE & Sup. & $\mathrm{AM}$ & $\mathrm{T}$ & And & media & no aéreo & $\mathrm{b}$ ajo & $>10 \mathrm{~mm}$ & sd & $\mathrm{sd}$ \\
\hline & 14 & $\mathrm{CE}$ & Sup. & $\mathrm{AM}$ & D & $\mathrm{Ba}$ & media & no aéreo & bajo & $>10 \mathrm{~mm}$ & sd & sd \\
\hline & 15 & CE & Sup. & $\mathrm{AM}$ & $\mathrm{T}$ & $\mathrm{Ba}$ & media & no aéreo & bajo & $>10 \mathrm{~mm}$ & $\begin{array}{c}>1,5 \\
\mathrm{~mm}\end{array}$ & $>45^{\circ}$ \\
\hline & 25 & $\mathrm{CE}$ & Sup. & $\mathrm{AM}$ & B & $\mathrm{Ba}$ & media & no aéreo & bajo & $>10 \mathrm{~mm}$ & $\begin{array}{c}>1,5 \\
\mathrm{~mm}\end{array}$ & $>45^{\circ}$ \\
\hline & 26 & $\mathrm{CE}$ & Sup. & $\mathrm{L}$ & $\mathrm{T}$ & $\mathrm{Ba}$ & media & indet & medio & $>10 \mathrm{~mm}$ & sd & sd \\
\hline & 28 & CE & Sup. & AM & $\mathrm{D}$ & $\mathrm{Ba}$ & media & no aéreo & bajo & $>10 \mathrm{~mm}$ & sd & $>45^{\circ}$ \\
\hline & 29 & $\mathrm{CE}$ & Sup. & $\mathrm{AM}$ & I & $\mathrm{Ba}$ & media & indet & $\mathrm{sd}$ & $>10 \mathrm{~mm}$ & sd & sd \\
\hline & 38 & CE & Sup. & AM & B & $\mathrm{Ba}$ & media & no aéreo & bajo & $>10 \mathrm{~mm}$ & $\begin{array}{c}1 \text { a } 1,5 \\
\mathrm{~mm}\end{array}$ & $>45^{\circ}$ \\
\hline & 31 & $\mathrm{CE}$ & Sup. & $\mathrm{AM}$ & $\mathrm{T}$ & $\mathrm{Ba}$ & media & indet & bajo & $>10 \mathrm{~mm}$ & sd & sd \\
\hline & 33 & CE & Sup. & $\mathrm{AM}$ & I & Sil & baja & indet & sd & $>10 \mathrm{~mm}$ & sd & sd \\
\hline & 46 & CE & Sup. & $\mathrm{AM}$ & $\mathrm{T}$ & $\mathrm{Ba}$ & media & no aéreo & bajo & $>10 \mathrm{~mm}$ & $>1,5$ & $\mathrm{sd}$ \\
\hline \multirow{3}{*}{ 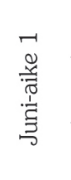 } & B44/21 & B & -94 & $\mathrm{~F}$ & M & And-Ba & media & normal & bajo & $>10 \mathrm{~mm}$ & sd & sd \\
\hline & B236/32 & B & $-85,5$ & $\mathrm{~F}$ & I & And-Ba & media & indet & $\mathrm{sd}$ & $>10 \mathrm{~mm}$ & sd & sd \\
\hline & $1987 / 17$ & Sup. & Sup. & $\mathrm{F}$ & B & $\mathrm{Ba}$ & media & normal & bajo & $<10 \mathrm{~mm}$ & sd & $\mathrm{sd}$ \\
\hline 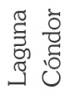 & 19 & Sup. & Sup. & $\mathrm{F}$ & B & $\mathrm{Ba}$ & media & perf. & bajo & $<10 \mathrm{~mm}$ & $<1 \mathrm{~mm}$ & $<45^{\circ}$ \\
\hline
\end{tabular}

de mano y las lanzas están predominantemente confeccionadas en rocas volcánicas oscuras, en cambio las flechas muestran un espectro más amplio de materias primas (Tablas 3 y 7). Todas estas rocas serían de provisión local, excepto la obsidiana verde que fue registrada en un pedúnculo de flecha del alero Potrok-aike (PA AL 393). Se utilizaron mayoritariamente rocas de tenacidad media (85\%) como andesitas y basaltos, y en menor proporción las de tenacidad baja (15\%), representadas por sílices, calcedonia y obsidiana. Los cabezales de los tres sistemas técnicos fueron elaborados con andesitas y basaltos, pero para las armas de mano y las flechas se usaron también rocas de tenacidad baja
(Tabla 3). Respecto del MODUREFU, se observó que en las lanzas es medio; mientras que en las armas de mano y las flechas -independientemente de la tenacidad de la roca empleada- es bajo.

En cuanto a la variable aerodinamia, resultó

Tabla 4. Funciones discriminantes en los centroides de los grupos (sistemas técnicos) conformados sobre la base de los atributos del enmangue.

\begin{tabular}{lcc}
\hline & \multicolumn{2}{c}{ Función } \\
\cline { 2 - 3 } \multicolumn{1}{c}{ Asignación funcional } & 1 & 2 \\
\hline Flecha & $-3,356$ &,- 560 \\
\hline Lanza &,- 498 &, 493 \\
\hline Arma de mano & 2,833 &,- 309 \\
\hline
\end{tabular}


Tabla 5. Grado de integridad de la muestra y localización de las fracturas por tipo de arma.

\begin{tabular}{|c|c|c|c|c|c|c|c|c|}
\hline \multirow[b]{2}{*}{$\begin{array}{l}\text { Tipo de } \\
\text { armas }\end{array}$} & \multicolumn{2}{|c|}{ Estado } & \multicolumn{6}{|c|}{ Posición de las fracturas según sistema de arma } \\
\hline & Enteros & Fracturadas & Ápice & $\begin{array}{l}\text { Limbo } \\
\text { Sup.erior }\end{array}$ & Aletas & $\begin{array}{c}\text { Raíz } \\
\text { pedúnculo }\end{array}$ & $\begin{array}{c}\text { Base } \\
\text { pedúnculo }\end{array}$ & Múltiples \\
\hline $\begin{array}{c}\text { Arma de } \\
\text { mano }\end{array}$ & 1 & 17 & - & 9 & - & 3 & 3 & 2 \\
\hline Lanza & - & 19 & - & - & 4 & 3 & - & 12 \\
\hline Flecha & 2 & 7 & 1 & 1 & - & 2 & - & 2 \\
\hline Totales & 3 & 43 & 1 & 10 & 4 & 8 & 3 & 16 \\
\hline
\end{tabular}

diagnóstica para discriminar sistemas técnicos con y sin almacenamiento de energía: imperfecta o indeterminada en las lanzas, perfecta o normal en las flechas y ausencia de aerodinamia en las armas de mano que no tienen trayectoria de vuelo (Tabla 7).

Respecto de los diseños, nueve cabezales no pudieron determinarse y ocho fueron descartados por presentar fracturas importantes en el limbo o en la raíz del pedúnculo. El mayor porcentaje de básicos corresponde a las flechas (22\%), siguiéndole las armas de mano (11\%) y las lanzas (10\%). Entre los mantenidos, los porcentajes más elevados se observaron entre las lanzas (26\%) y las flechas (22\%), siendo bajos entre las armas de mano (5,5\%). Por último, los transformados alcanzan las frecuencias más altas y parejas entre las armas de mano y las lanzas (39 y $42 \%$ respectivamente), mientras que entre las flechas no superan el $11 \%$. Las puntas destacadas $(n=5)$ y las puntas entre muescas $(n=4)$ son los subgrupos tipológicos más representados en el conjunto de los transformados.

Para reconocer la vinculación entre las actividades de transformación y los cambios en la alometría del diseño se calcularon los índices de Reavivamiento y de Robustez para 32 piezas. La correlación (r Pearson) entre las variables métricas y ambos índices muestran (Tabla10):

a) una correlación significativa de magnitud alta y negativa del largo del limbo versus el Índice de Reavivamiento $(\mathrm{r}=-0,708)$, lo que indica procesos de mantenimiento con reducción del largo de la pieza. La correlación entre el ancho del limbo versus el Índice de Reavivamiento es también negativa $(\mathrm{r}=$
$-0,504)$, pero la fuerza de la correlación entre las variables es menor que en el caso del largo. Esto señala una leve tendencia a modificar los anchos de las piezas en el proceso de mantenimiento. Finalmente, la correlación con el resto de las variables (espesor del limbo y largo/ancho/espesor del pedúnculo) es muy baja o nula, por lo tanto se interpreta que no hubo modificación de las mismas durante el proceso de mantenimiento.

b) con respecto al indice de Robustez se obtuvo baja correlación con el largo del limbo $(\mathrm{r}=0,206)$, mientras que es media-alta en los casos del ancho y espesor del limbo ( $r=0,621$ y $r=0,789$, respectivamente), y el ancho y espesor del pedúnculo $(r=0,699$ y $r=0,733$, respectivamente). En consecuencia, se infiere que la robustez fue lograda a partir de la modificación del ancho y espesor más que del largo.

Los tres sistemas técnicos mostraron una distribución espacial diferencial: en los sitios de superficie predominan las armas de mano seguidas por las lanzas y sólo se hallaron dos puntas de flecha (Tabla 3). Por el contrario, en los abrigos rocosos hay ausencia de armas de mano (excepto dos ejemplares en el Reparo) y la proporción de flechas es mayor. En cuanto a la distribución temporal intersitio, en el alero Potrok-aike sólo se registraron puntas en los niveles medios y tardíos $(-0,97 \mathrm{~m}$ a $-0,20 \mathrm{~m})$ que cubren un rango temporal entre 1200 años ${ }^{14} \mathrm{C}$ AP y tiempos postcontacto (Tabla 2). Las de lanza se hallaron en ambos niveles, mientras que las de flecha recién a partir del más moderno (de -0,67 m hacia arriba) 
Tabla 6. Atributos métricos considerados (valores en milímetros).

\begin{tabular}{|c|c|c|c|c|c|c|c|c|c|c|c|c|c|c|}
\hline $\mathrm{N}^{\circ}$ punta & Asig & Descrip & $\begin{array}{l}\text { Lar } \\
\text { Max }\end{array}$ & $\begin{array}{l}\text { Lar } \\
\text { Max } \\
\text { Infer }\end{array}$ & $\begin{array}{l}\text { Lim } \\
\text { Lar }\end{array}$ & $\begin{array}{l}\text { Lim } \\
\text { Lar } \\
\text { Infer }\end{array}$ & Conf & $\begin{array}{l}\mathrm{Lim} \\
\text { Anc }\end{array}$ & $\begin{array}{l}\text { Lim } \\
\text { Esp } \\
\text { Max }\end{array}$ & $\begin{array}{l}\text { Ped } \\
\text { Lar }\end{array}$ & $\begin{array}{l}\text { Ped } \\
\text { Anc } \\
\text { Base }\end{array}$ & $\begin{array}{l}\text { Ped } \\
\text { Anc } \\
\text { Raíz }\end{array}$ & $\begin{array}{l}\text { Esp } \\
\text { Max }\end{array}$ & $\begin{array}{l}\text { Ubic } \\
\text { Esp } \\
\text { Max }\end{array}$ \\
\hline III S - 34 & $\mathrm{~L}$ & Ped & 17,28 & 32,19 & 6,69 & 21,69 & $65 \%$ & 17,37 & 4,12 & 10,5 & 14,1 & 13,27 & 5,64 & Raíz \\
\hline $16-20$ & $\mathrm{~F}$ & Ped & 17,6 & 17,7 & 12,61 & 12,62 & $90 \%$ & 12,84 & 3,48 & 4,99 & 5,4 & 5,4 & 2,55 & LimBase \\
\hline B107-22 & $\mathrm{L}$ & Ped & 28,15 & 36,44 & 16,1 & 24,39 & $50 \%$ & 24 & 5,89 & 12,05 & 17,3 & 14,84 & 5,63 & LimBase \\
\hline A107/8 & $\mathrm{L}$ & Ped & 27,5 & 35,83 & 16,19 & 24,52 & $85 \%$ & 23,8 & 6,09 & 11,31 & 13,9 & 12,2 & 5,8 & LimBase \\
\hline $188-37$ & $\mathrm{~L}$ & Frag Ped" & 11,55 & $\mathrm{nc}$ & $\mathrm{nc}$ & $\mathrm{nc}$ & $\mathrm{nc}$ & $\mathrm{nc}$ & $\mathrm{nc}$ & 11,55 & 16,98 & 16,6 & 7,7 & $\mathrm{nc}$ \\
\hline $138-23$ & $\mathrm{~F}$ & Ped & 19,98 & 29,38 & 9,49 & 18,89 & $85 \%$ & 21,2 & 4,44 & 10,49 & 13,4 & 11,6 & 5,1 & Raíz \\
\hline $293-47 / 52$ & $\mathrm{~F}$ & Pedúnc & 18 & $\mathrm{nc}$ & 13,1 & $\mathrm{nc}$ & $\mathrm{nc}$ & 14,3 & $\mathrm{nc}$ & 4,9 & 10,6 & 8,2 & 4,4 & $\mathrm{nc}$ \\
\hline A445-35 & $\mathrm{L}$ & Ped & 24,55 & 36,08 & 14,85 & 26,38 & $85 \%$ & 27,1 & 5,4 & 9,7 & 15,5 & 13,8 & 5,5 & Raíz \\
\hline $27-44$ & $\mathrm{~L}$ & Ped & 31,1 & 31,1 & 23 & 23 & $100 \%$ & 24,7 & 5,54 & 8,1 & 13,9 & 13,9 & 5 & Raíz \\
\hline $30-45 / 50$ & $\mathrm{~L}$ & Ped & 46,39 & 48,14 & 30,35 & 32,1 & $95 \%$ & 26,61 & 5,9 & 15,95 & 17,36 & 17,03 & 9,04 & $\mathrm{nc}$ \\
\hline $494-49$ & $\mathrm{~L}$ & Ped & 45,2 & 34,1 & 34,1 & $\mathrm{nc}$ & $\mathrm{nc}$ & 33,6 & $\mathrm{nc}$ & 11,1 & 17,8 & 14,3 & 5,3 & $\mathrm{nc}$ \\
\hline $571-18$ & $\mathrm{~L}$ & Ped & 26,38 & 37,36 & 10,98 & 21,96 & $50 \%$ & 18 & 3,8 & 15,4 & 17,9 & 14 & 6,8 & MitadPed \\
\hline $569-16$ & $\mathrm{~L}$ & Ped & 33,17 & 38,12 & 20,02 & 24,97 & $70 \%$ & 25 & 5,33 & 13,15 & 16,8 & 15,2 & 6,6 & Raíz \\
\hline B445-48 & $\mathrm{L}$ & Pedúnc & $\mathrm{nc}$ & $\mathrm{nc}$ & nc & nc & $\mathrm{nc}$ & $\mathrm{nc}$ & $\mathrm{nc}$ & 13,28 & 20,95 & 21,33 & 7,68 & $\mathrm{nc}$ \\
\hline $572-11$ & $\mathrm{~L}$ & Ped & 30,06 & 41,56 & 19,82 & 31,32 & $70 \%$ & 22,6 & 5,14 & 10,24 & 10,39 & 12,4 & 4,96 & LimBase \\
\hline 41 & $\mathrm{~F}$ & Ped & 25,56 & 37,92 & 18,86 & 31,22 & $85 \%$ & 18,55 & 3,79 & 6,7 & 10,21 & 9,23 & 3,69 & LimBase \\
\hline $14-40$ & AM & Pedúnc & $\mathrm{nc}$ & $\mathrm{nc}$ & $\mathrm{nc}$ & $\mathrm{nc}$ & $\mathrm{nc}$ & nc & $\mathrm{nc}$ & 10,74 & 17,9 & 17,9 & 6,1 & $\mathrm{nc}$ \\
\hline $15 / 13-51$ & $\mathrm{~L}$ & Pedúnc & $\mathrm{nc}$ & $\mathrm{nc}$ & $\mathrm{nc}$ & $\mathrm{nc}$ & $\mathrm{nc}$ & $\mathrm{nc}$ & $\mathrm{nc}$ & 11,2 & 17,4 & 15,9 & 5,3 & $\mathrm{nc}$ \\
\hline 12_24 & $\mathrm{AM}$ & Pedúnc & $\mathrm{nc}$ & $\mathrm{nc}$ & $\mathrm{nc}$ & $\mathrm{nc}$ & $\mathrm{nc}$ & $\mathrm{nc}$ & $\mathrm{nc}$ & 12,8 & 13,8 & 18 & 4,2 & $\mathrm{nc}$ \\
\hline $285-42$ & AM & Ped & 36 & 43,87 & 18,93 & 33,8 & $85 \%$ & 34,05 & 8,51 & 17,07 & 22,58 & 21,55 & 9.27 & Raíz \\
\hline 7 & $\mathrm{~F}$ & Ped & 20,42 & 24,69 & 13,06 & 17,33 & $85 \%$ & 17,05 & 4,08 & 7,36 & 1,95 & 12,5 & 4,2 & Raíz \\
\hline $500-13$ & $\mathrm{AM}$ & Ped & 34,83 & 38,33 & 20,78 & 24,28 & $85 \%$ & 24,86 & 6,43 & 14,05 & 18,08 & 19,42 & 6,6 & Raíz \\
\hline $501-12$ & $\mathrm{~L}$ & Ped & 29,69 & 32,19 & 19,73 & 22,23 & $95 \%$ & 26,05 & 5,12 & 9,96 & 12,32 & 12,55 & 5,1 & LimBase \\
\hline $31 / 27$ & $\mathrm{AM}$ & Aped & 49,27 & 78,69 & 49,78 & 79,25 & $75 \%$ & 41,44 & 6,66 & $\mathrm{nc}$ & nc & 13,4 & $\mathrm{nc}$ & Raíz \\
\hline $65 / 30$ & $\mathrm{AM}$ & Pedúnc & 39,69 & $\mathrm{nc}$ & 39,69 & 41,69 & $50 \%$ & 29,34 & 6,2 & $\mathrm{nc}$ & nc & 17,03 & 5,73 & Raíz \\
\hline 10 & $\mathrm{AM}$ & Ped & 32,15 & 41,45 & 21,75 & 31,05 & $85 \%$ & 24,6 & 7,45 & 10,4 & 16,66 & 17,8 & 6,08 & LimBase \\
\hline $499 / 4$ & $\mathrm{~L}$ & Ped & 38,18 & 44,35 & 23,95 & 30,12 & $85 \%$ & 24,29 & 6,41 & 14,23 & 16,75 & 13,61 & 7,2 & Raíz \\
\hline 1 & $\mathrm{~L}$ & Ped & 41,04 & 50,51 & 25,09 & 31,02 & $70 \%$ & 24,84 & 8,27 & 16,56 & 20,34 & 17,95 & 9,3 & Raíz \\
\hline 2 & $\mathrm{~L}$ & Ped & 35,86 & 43,77 & 28,94 & 38,41 & $70 \%$ & 33,32 & 7,76 & 12,1 & 19,74 & 16,22 & 7,6 & Raíz \\
\hline 3 & $\mathrm{~L}$ & Ped & 38,18 & 44,35 & 26,38 & 34,29 & $70 \%$ & 30,76 & 6,12 & 9,48 & 14,99 & 15,1 & 5,7 & LimBase \\
\hline 6 & AM & Ped & 64,69 & 73,94 & 42,27 & 52,02 & $80 \%$ & 38,52 & 7,71 & 21,92 & 19,75 & 22 & 7,5 & LimBase \\
\hline 9 & $\mathrm{AM}$ & Ped & 40,49 & 43,64 & 26 & 29,15 & $95 \%$ & 29,44 & 6,02 & 14,49 & 17,95 & 18,1 & 5,9 & LimBase \\
\hline 14 & $\mathrm{AM}$ & Ped & 45,5 & 61,54 & 28,69 & 44,73 & $50 \%$ & 44,17 & 9,11 & 16,81 & 21,27 & 21,46 & 9,34 & Raíz \\
\hline 15 & AM & Ped & 50,26 & 62,97 & 45,34 & 54,88 & $50 \%$ & 36,06 & 8,79 & $\mathrm{nc}$ & $\mathrm{nc}$ & 20,43 & 8,5 & Raíz \\
\hline 25 & AM & Ped & 55,54 & 55,54 & 32,38 & 32,38 & $100 \%$ & 34,48 & 7,58 & 23,16 & 15,32 & 20,57 & 7,82 & Raiz \\
\hline 26 & $\mathrm{~L}$ & Ped & 37,46 & 48,67 & 22,27 & 33,48 & $60 \%$ & 28,81 & 7,44 & 15,19 & $\mathrm{nc}$ & 17,8 & 7,26 & LimBase \\
\hline 28 & $\mathrm{AM}$ & Pedúnc & 44,46 & $\mathrm{nc}$ & 39,95 & 42,37 & $50 \%$ & 35,18 & 6,17 & $\mathrm{nc}$ & $\mathrm{nc}$ & 23 & 5,72 & LimCentro \\
\hline 29 & $\mathrm{AM}$ & Ped & 19,36 & 51,75 & 6,92 & 39,31 & $50 \%$ & 35,19 & 6,83 & 12,44 & 18,16 & 19,46 & 6,75 & LimBase \\
\hline 38 & AM & Ped & 48,74 & 51,24 & 31,05 & 33,55 & $90 \%$ & 27,73 & 5,12 & 17,69 & 12,67 & 18,71 & 5,98 & Raíz \\
\hline 31 & $\mathrm{AM}$ & Pedúnc & 21,16 & 43,49 & 7,05 & 29,38 & $30 \%$ & $\mathrm{nc}$ & 6,99 & 14,11 & 22,61 & 18,77 & 7,24 & Raíz \\
\hline 33 & $\mathrm{AM}$ & Ped & 28,58 & 41,79 & 13,19 & 26,4 & $50 \%$ & 21,5 & 7,49 & 15,39 & 16,47 & 20,3 & 7,4 & LimBase \\
\hline 46 & AM & Ped & 41,18 & 47,03 & 25,19 & 31,04 & $70 \%$ & 27,65 & 6,39 & 15,99 & 18,7 & 18,99 & 7,4 & Raíz \\
\hline B44-21 & $\mathrm{F}$ & Ped & 23,18 & 26,65 & 17,6 & 21,07 & $70 \%$ & 22,87 & 5,01 & 5,58 & 10,68 & 11,16 & 4,7 & LimCentro \\
\hline B 236-32 & $\mathrm{F}$ & Pedúnc & 9,37 & $\mathrm{nc}$ & $\mathrm{nc}$ & $\mathrm{nc}$ & $\mathrm{nc}$ & $\mathrm{nc}$ & $\mathrm{nc}$ & 7,94 & 13,56 & 11,36 & 4,04 & $\mathrm{nc}$ \\
\hline $1987-17$ & $\mathrm{~F}$ & Ped & 29,96 & 33,99 & 20,57 & 24,6 & $85 \%$ & 16,87 & 4,91 & 9,39 & 14,19 & 13,05 & 5,3 & Raíz \\
\hline 19 & $\mathrm{~F}$ & Ped & 15,76 & 15,76 & 9,35 & 9,35 & $100 \%$ & 15,1 & 3 & 6,42 & 6,59 & 6,32 & 2,9 & LimBase \\
\hline
\end{tabular}

Referencias: Asig: Asignación funcional; Descrip: descripción; Ped: cabezales pedunculados; Aped: cabezales apedunculados; Pedúnc: piezas representadas sólo por el pedúnculo; LarMax: largo máximo; LarMaxInfer: largo máximo inferido; LimLar: largo del limbo; LimLarInfer: largo del limbo inferido; Conf: porcentaje de confiabilidad; LimAnc: ancho del limbo; LimEsp: espesor del limbo; PedLar: largo del pedúnculo; PedAncBase: ancho de la base del pedúnculo; PedAncRaíz: ancho de la raíz del pedúnculo; EspMax: máximo espesor; LimBase: base del limbo; LimbCentro: centro del limbo; nc: no corresponde. 
Tabla 7. Frecuencia absolutas y relativas entre sistemas de arma y materias primas.

\begin{tabular}{lcccccc}
\hline \multicolumn{1}{c}{ Arma } & Basalto & And-Basalto* & Andesita & Sílices & Calced & Obsid \\
\hline Arma de mano & $13(72 \%)$ & $1(5,5 \%)$ & $1(5,5 \%)$ & $2(11 \%)$ & $1(5,5 \%)$ & -- \\
\hline Lanza & $7(37 \%)$ & $11(58 \%)$ & -- & -- & $1(5 \%)$ & -- \\
\hline Flecha & $3(33 \%)$ & $3(33 \%)$ & -- & $1(11 \%)$ & $1(11 \%)$ & $1(11 \%)$ \\
\hline Totales & 23 & 15 & 1 & 3 & 3
\end{tabular}

* And-Basalto: andesita - basalto.

(Tabla 3). De las asignadas a flecha, una es "tipo Ona" (PA Al S 16) y dos son similares a las Bird IV, aunque de menor tamaño y espesor (Gómez Otero 1987, 1988: Fig. 3, 6). La punta tipo Ona fue hallada a $-0,35 \mathrm{~m}$ en un estrato datado en $740 \mathrm{AP}$; las otras se rescataron entre $-0,67 \mathrm{~m}$ y $-0,64 \mathrm{~m}$. A menor profundidad $(-0,20 \mathrm{~m})$ se registró una punta asignada a lanza que estaba en un nivel superior a un fogón datado en 360 años ${ }^{14} \mathrm{C}$ AP (Gómez Otero 1987). En el Reparo se registraron tres pedúnculos entre $-0,70 \mathrm{~m} \mathrm{y}$ $-0,60 \mathrm{~m}$ : dos fueron determinados como armas de mano y el otro como lanza.

Por su parte en el alero Juni-aike 1 (Gómez Otero 1994) se hallaron cabezales en todos los niveles culturales, pero no en los estratos más profundos (entre - 1,48 m y -1,30 m) (Tabla 3). De acuerdo con la asignación efectuada anteriormente por Ratto (1994), las puntas de lanza fueron registradas entre -1,31 $\mathrm{m}$ y $-0,85 \mathrm{~m}$, el arma de mano a $-1,20 \mathrm{~m}$ y las flechas entre $-0,94 \mathrm{~m}$ y $-0,72 \mathrm{~m}$. Con relación a la cronología, se obtuvo una única datación
Tabla 8. Sistemas de armas y aerodinamia.

\begin{tabular}{lcccc}
\hline Aerodinamia & $\begin{array}{c}\text { Arma de } \\
\text { mano }\end{array}$ & Lanzas & Flechas & Totales \\
\hline Perfecta & -- & -- & 3 & 3 \\
\hline Imperfecta & 1 & 11 & - & 12 \\
\hline No aerodinámica & 11 & -- & - & 11 \\
\hline Normal & 1 & -- & 4 & 5 \\
\hline Indeterminada & 5 & 8 & 2 & 15 \\
\hline
\end{tabular}

(850 $\pm 40 \mathrm{C}^{14}$ AP) de un fogón a 1,04 m de profundidad. Un esqueleto de vacuno juvenil fue registrado sobre los niveles superiores; esto indica que las últimas ocupaciones se habrían dado poco antes de la introducción del ganado europeo a mediados del siglo XIX.

\section{DISCUSIÓN}

La aplicación de la nueva versión del modelo de asignación funcional de Ratto (2003; 2012) corroboró que en el área de estudio se utilizaron tres sistemas de arma: de mano, lanza, y arco

Tabla 9. Sistemas de armas y diseño.

\begin{tabular}{|c|c|c|c|c|c|c|c|c|c|c|c|c|}
\hline \multirow{2}{*}{ 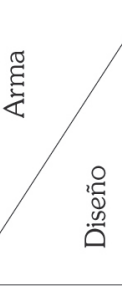 } & \multirow[b]{2}{*}{ 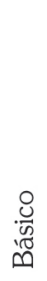 } & \multirow[b]{2}{*}{ 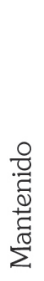 } & \multicolumn{7}{|c|}{ Transformado } & \multirow[b]{2}{*}{ 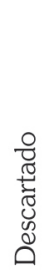 } & \multirow[b]{2}{*}{ 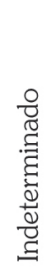 } & \multirow[b]{2}{*}{$\frac{\mathscr{Q}}{\frac{O}{0}}$} \\
\hline & & & $\frac{\stackrel{0}{\bar{Z}}}{\frac{\mathrm{J}}{\mathrm{J}}}$ & 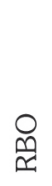 & 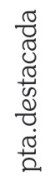 & 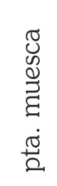 & 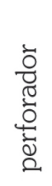 & 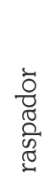 & $\frac{\stackrel{0}{ \pm}}{\frac{ \pm}{U}}$ & & & \\
\hline $\mathrm{AM}$ & 2 & 1 & 2 & -- & 2 & 1 & 1 & 1 & -- & 4 & 4 & 18 \\
\hline $\mathrm{L}$ & 2 & 5 & - & 2 & 3 & 2 & -- & - & 1 & 1 & 3 & 19 \\
\hline $\mathrm{F}$ & 2 & 2 & 1 & -- & -- & -- & -- & - & -- & 2 & 2 & 9 \\
\hline $\begin{array}{l}\text { Totales } \\
(n=47)\end{array}$ & 6 & 8 & & & & 16 & & & & 8 & 9 & 47 \\
\hline
\end{tabular}


Tabla 10. Estadística descriptiva de los índices de reavivamiento y de robustez.

\begin{tabular}{|c|c|c|c|c|c|c|}
\hline \multirow{2}{*}{ Estadístico } & \multicolumn{3}{|c|}{ Îndice de reavivamiento } & \multicolumn{3}{|c|}{ Îndice de robustez } \\
\hline & Flecha & Lanza & Arma de mano & Flecha & Lanza & Arma de mano \\
\hline$N=46$ & $7: 9$ & $14: 19$ & $11: 18$ & $7: 9$ & $14: 19$ & $11: 18$ \\
\hline Media & 0,168 & 0,162 & 0,143 & 2,972 & 4,014 & 4,595 \\
\hline Mediana & 0,173 & 0,160 & 0,140 & 2,874 & 4,068 & 4,309 \\
\hline Desv. Stand. & 0,034 & 0,019 & 0,039 & 0,802 & 0,615 & 1,329 \\
\hline Mínimo & 0,099 & 0,124 & 0,064 & 1,830 & 2,795 & 2,633 \\
\hline Máximo & 0,198 & 0,197 & 0,210 & 4,299 & 4,921 & 7,141 \\
\hline Asimetría & $-1,805$ & $-0,060$ & $-0,372$ & 0,481 & $-0,560$ & 0,768 \\
\hline Curtosis & 3,596 & 0,485 & 0,760 & 0,349 & 0,074 & 0,506 \\
\hline
\end{tabular}

y flecha. En la muestra analizada el pedúnculo resultó ser la parte del cabezal más conservada e idiosincrática, lo que posibilitó su asignación funcional a través del uso de pruebas estadísticas.

En superficie se hallaron ejemplares de todos los sistemas; sin embargo en los sitios estratificados se observó ausencia de puntas asignadas a arma de mano (salvo los dos cabezales del Reparo). Si se tiene en cuenta que estos y otros aleros chicos del área, como Peggy Bird (Prieto Iglesias 1989-90), El Volcán 4 (Nami 1984) y Pali-aike 2 (Massone y Hidalgo 1981), fueron ocupados recién en el Holoceno tardío se podría hipotetizar que para esa fecha el uso de armas de mano estaba en declinación. No obstante, la asociación contextual de puntas de lanza y arma de mano registrada en el Reparo, sugiere que ambos sistemas podrian haberse implementado simultáneamente, por lo menos durante un tiempo. La presencia y predominio de puntas de lanzas en todas las ocupaciones indica que este sistema técnico fue el más utilizado a pesar de no ser seguro en términos de eficacia en la caza (Ratto 2003). Esto sugiere que sus deficiencias técnicas habrían sido contrarrestadas mediante su uso en cacerías grupales al acecho o en situación de desventaja de las presas, tal como plantea el MAF. En este sentido, topografías como las del área de estudio propician la caza por acecho. Por último, el registro de flechas en niveles posteriores a 900-800 AP refuerza la hipótesis que el arco y la flecha fueron una innovación tecnológica que se agregó al repertorio ya existente de armas
(Massone 1981; Gómez Otero 1987). Si bien los reemplazos técnicos pueden atribuirse a distintas causas, indudablemente este sistema garantizó mayor éxito y flexibilidad en la cacería ya que por una parte es seguro (Ratto 2003) y por otra permite su implementación tanto en la caza en grupo como en solitario (Churchill 1993).

La selección prioritaria de nódulos de rocas locales oscuras de buena calidad para la talla para todos los tipos de armas y el uso de mayor variedad de materias primas para las flechas (algunas no locales, como la obsidiana verde), fueron también registrados en otros sitios del CVPA (Prieto 1989-90; Nami 1999). Justamente Nami (1999) determinó el uso de lascas en vez de preformas bifaciales para la elaboración de flechas, lo que relacionó con una estrategia de optimización en el aprovechamiento de nódulos chicos de materias primas poco abundantes o alóctonas en el área. La obsidiana gris verdosa es la más representada en los conjuntos artefactuales del CVPA (Charlin 2009). Su probable fuente se hallaría en la zona cordillerana de sierra de Los Baguales, a unos $200 \mathrm{~km}$ de distancia del área de estudio (Stern \& Franco 2000). La verde no veteada (como la del pedúnculo de flecha del alero Potrok-aike 1) procedería de algún lugar del archipiélago del mar de Skyring (Stern \& Prieto 1991); por lo tanto su presencia en el área podría deberse a intercambio directo o indirecto con canoeros que circulaban por el estrecho de Magallanes, distante unos 50 $\mathrm{km}$ hacia el sudeste.

En cuanto al índice de fracturas, las 
diferencias entre los tres sistemas técnicos se vincularían con el desempeño de cada uno (Ratto 2003: Tablas 5.1. y 5.2 a). En las lanzas la trayectoria de vuelo es inestable, por lo tanto hay un alto riesgo de fracturas por el pandeo del astil o el choque con huesos, obstáculos o el suelo. Esto habría propiciado el uso de materias primas de tenacidad media y el refuerzo en la zona del enmangue. En las otras armas el riesgo de fracturas es menor: las de mano no son arrojadizas y las flechas tienen una trayectoria de vuelo estable. En tal sentido, sus respectivos cabezales fueron confeccionados con rocas de tenacidad baja a media y no se observaron módulos elevados de refuerzo. Sin embargo, hay que destacar la alta frecuencia de flechas fracturadas en la muestra (sólo dos enteras). Prieto Iglesias (1989-90: 79, 83) también registró un elevado porcentaje de fracturas (94\%) entre las puntas de flecha del sitio tardío "Alero Peggy Bird", atribuyéndolo a la caída del animal sobre el arma o al impacto del ápice contra el suelo. Respecto de los pedúnculos, tanto en nuestra muestra como en los aleros El Volcán 4 (Nami 1984) y Peggy Bird (Prieto Iglesias 1989-90), están fracturados en la raíz o zona de contacto entre el limbo y el pedúnculo. Según Nami y Prieto Iglesias, podría deberse a que fueron enmangadas con tientos que cubrieron todo el pedúnculo hasta la raíz. Al respecto, un análisis de microdesgaste realizado por Franco et al. (2009) señaló el uso de tientos para el enmangue de puntas pedunculadas recuperadas al sur del río Santa Cruz.

Con relación a los diseños, si bien la gran mayoría de las armas de mano y de lanza presenta el diseño característico del Período IV, una punta triangular apedunculada similar a las del Período III del Holoceno medio fue asignada a arma de mano. Esto sugiere la posibilidad de que a partir del Holoceno tardío se haya producido el paulatino reemplazo de los cabezales apedunculados, originalmente utilizados en las armas de mano, por los de pedúnculo ancho $y$ espeso. Justamente, sobre la base de la anchura y espesor del pedúnculo, Franco et al. (2010) definen un diseño denominado "Magallanes IV espesas", que se habría originado circa 3000 AP en la zona del estrecho de Magallanes y perdurado sin modificaciones sustanciales hasta tiempos post-contacto. Desde esa zona nuclear habría expandido su área de dispersión hasta el nordeste de la provincia de Chubut inclusive (Franco et al. 2010). Según las autoras esto se debería a la conservación y replicación de un diseño exitoso (sensu Bettinger \& Eerkens 1999), adoptado más por mecanismos de intercambio de información que por circulación de objetos terminados. La presencia de puntas de pedúnculo ancho y espeso en todos los niveles tardíos de sitios del CVPA -incluidos los discutidos en este trabajo- avala la hipótesis de mantenimiento de un diseño exitoso.

En cuanto a los cabezales que exhiben el diseño típico del Período IV pero fueron atribuidos a flecha, es importante destacar que, a diferencia de los de lanza, son más pequeños y delgados, sobre todo en la raíz del pedúnculo. No obstante, este sector de la pieza sigue siendo el de máximo espesor. Esto señalaría la adaptación formal de las pedunculadas espesas para su uso en un sistema más eficaz como el arco y la flecha. Tal resultado contrasta con el estudio de morfometría geométrica realizado por González-José y Charlin (2012) a través del cual las puntas adjudicadas a flecha corresponden solamente a las Bird V o tipo Ona (Tipo I). La discrepancia en la asignación se debería a que no se consideraron los atributos espesor, tenacidad de la roca y módulo de refuerzo. En cuanto a los ejemplares tipo "Ona", su frecuencia en los sitios es menor y más tardía (posterior a $800 \mathrm{AP}$ ). Dadas las semejanzas con cabezales del norte de Tierra del Fuego (Borrero et al. 2008), es probable que este diseño haya ingresado al área a través de mecanismos de intercambio, como los ya probados para materias primas no locales como la obsidiana verde (Morello et al. 2004).

La transformación de algunas piezas en otros grupos tipológicos, tales como puntas destacadas, puntas entre muescas, filos retocados en bisel oblicuo y raspadores, fue también registrada en el estrecho de Magallanes (Ortiz Troncoso 1972: 58). Esto sería más esperable en situaciones de ausencia o escasez de materias primas líticas aptas para la talla, que no sería el caso del CVPA dada la disponibilidad de rocas oscuras de grano fino de buena calidad. Sin embargo, es importante considerar que las de mejor calidad ("tipo Potrokaike") presentan una distribución acotada a ciertos 
sectores del interfluvio (Charlín \& Pallo 2013).

Con relación a las maderas probablemente empleadas para la confección de astiles y arcos, si bien hasta el momento no hay registro arqueológico ni etnográfico de $\operatorname{arcos} y$ astiles de flecha para el área, se infiere el doble aprovechamiento de maderas de la estepa (como el calafate) y también especies propias de los bosques andino-patagónicos que pudieron ser obtenidas directamente o por intercambio.

\section{CONSIDERACIONES FINALES}

Este trabajo permitió conocer que en el Holoceno tardío los cazadores-recolectores de Patagonia meridional utilizaron al menos tres sistemas de armas diferentes: de mano, lanzas y flechas propulsadas por arco. De acuerdo con la distribución temporal de la muestra aquí tratada se observa que: a) las armas de mano parecen haber sido empleadas antes que las lanzas; b) las lanzas habrían estado en uso desde por lo menos 2000 AP y tiempos postcontacto; y c) el arco y la flecha se habrían incorporado circa 900-800 AP.

El empleo de diseños característicos del Período IV para los cabezales de los tres tipos de arma sugiere mecanismos de trasmisión $y$ mantenimiento de un diseño exitoso caracterizado por el pedúnculo ancho y espeso. Las características distintivas del pedúnculo refuerzan el valor diagnóstico de este sector de la pieza no sólo para la asignación funcional sino también como marcador de señales de tipo idiosincrático.

A modo de conclusión, la asignación funcional de un conjunto de cabezales líticos permitió ampliar el conocimiento sobre las estrategias de caza y las decisiones técnicas implementadas por los cazadores de Patagonia meridional a lo largo del Holoceno tardío. Esta herramienta heurística permitió "acceder" a tales comportamientos mediante la interrelación no sólo de variables ecológicas, sino también sociales y de diseño.

\section{AGRADECIMIENTOS}

Queremos expresar nuestro agradecimiento al Dr. Miguel Haller y a la Dra. Gabriela Massaferro por la determinación petrográfica de las muestras, así como a la Dra. Judith Charlin por los comentarios realizados en versiones previas de este trabajo y por compartir información sobre algunas de las fuentes de abastecimiento de rocas en el CVPA. También agradecemos la colaboración de Jorge Briguglio y Juan Saavedra (CENPAT) por el procesamiento de las imágenes. Por último, se agradecen los valiosos comentarios de la Dra. Judith Charlin, que permitieron mejorar y aclarar aspectos del manuscrito original. Estos trabajos contaron con el financiamiento del PICT 19-26040, otorgado a Nora Franco, y el PIP-CONICET 6470, otorgado a Julieta Gómez Otero.

\section{BIBLIOGRAFÍA}

Aschero, C., S. Hocsman \& N. Ratto. (2011). Las puntas de proyectil "en mandorla" de Inca Cueva 7: Caracterización tipológica e historia de vida (Puna de Jujuy, Argentina). Estudios Atacameños 41,5-28.

Bate, L. F. (1978-79). Las investigaciones sobre los cazadores tempranos en Chile Austral. Trapananda 1(2), 14-23.

Belardi, J.B., F. Carballo Marina \& G.L. L'heureux. (2011). Nuevos resultados arqueológicos en Cabo Vírgenes (Santa Cruz, Argentina): el sitio Cabo Virgenes 20. Magallania 39(2), 279-292.

Bettinger, R. L. \& J. Eerkens. (1999). Point Typologies, Cultural Transmission, and the Spread of Bow-and-Arrow Technology in the Prehistoric Great Basin. American Antiquity 64(2), 231-242.

Bird, J. (1938). Antiquity and migrations of the early inhabitants of Patagonia. The Geographical review 28, 250-275.

Bird, J. (1988). Viajes y Arqueología en Chile Austral. J. Hyslop (Ed.). Punta Arenas: Ediciones de la Universidad de Magallanes.

Borrero, L.A., J. Charlin, R. Barberena, F. Martin, K. Borrazzo \& G. L'Heureux. (2008). Circulación humana y modos de circulación al sur del río Santa Cruz. En L. A. Borrero, y N. Franco (Eds.), Arqueología del extremo sur del continente americano. Resultados de nuevos proyectos (pp.155-174). Buenos Aires: CONICET-IMHICIHU.

Cardillo, M. (2005). Explorando la variación en las morfologías líticas a partir de la técnica de análisis de contornos. El caso de las puntas de proyectil del holoceno mediotardío de la Puna de Salta (San Antonio de los Cobres, Argentina). Werken 7, 77-88.

Caruso Fermé, L., M. Álvarez \& M. Vázquez. (2011). Análisis arqueobotánico de piezas de madera del extremo austral americano. Magallania 39(1), 221-240. 
Castiñeira C, M. Cardillo, J. Charlin, J. C. Fernicola \& J. Baeza. (2009). Análisis morfométrico de cabezales líticos "cola de pescado" de la Rep. Oriental del Uruguay. En Arqueometría Latinoamericana, Actas del Segundo Congreso Argentino y 1ro Latinoamericano. Vol. 2: 360-366. Buenos Aires.

Chapman, A. (1986). Los Selḱnam. La vida de los onas. Buenos Aires: Emecé Editores.

Charlín J. (2009). Estrategias de aprovisionamiento y utilización de las materias primas líticas en el campo volcánico Pali Aike (Prov. de Santa Cruz, Argentina). Oxford: Archaeopress, BAR International Series 1901.

Charlin, J, N. Franco \& M. D' Orazio. (2010). El Campo Volcánico Pali Aike y las fuentes potenciales de aprovisionamiento lítico: primeros resultados geoquímicos. En L. A. Borrero \& J. Charlin (Eds), Arqueología de Pali Aike y Cabo Vírgenes Buenos Aires: Editorial Dunken.

Charlin, J. \& M. Pallo, (2013). Disponibilidad de materias primas líticas y uso del espacio en el interfluvio Gallegos-Chico (Pali Aike, Santa Cruz, Argentina). En A.F. Zangrando, R. Barberena, A. Gil, G. Neme, M. Giardina, L. Luna, C. Otaola, S. Paulides, L. Salgán y A. Tívoli (Eds.). Tendencias teórico-metodológicas y casos de estudio en la arqueología de la Patagonia, pp. 307-316. San Rafael: Museo de Ciencias Naturales de San Rafael, INAPL, SAA.

Charlin, J \& R. González-José. (2012). Size and shape variation in Late Holocene projectile points of Southern Patagonia: a geometric morphometric study. American Antiquity 77 (2), 221-242.

Churchill, S. (1993). Weapon technology, prey size selection and hunting methods in modern hunter-gatherer: implications for hunting in the Paleolithic and Mesolithic. En G.L. Peterkin, H.Bricker \& P. Mellars (Eds.). Hunting and Animal Exploitation in the Later Paleolithic and Mesolithic of Eurasia. New York: Archaeological Papers of the American Anthropological Association

Emperaire, J. Laming-Emperaire, Reichlen, H. \& Joisen Th. (1963). La grotte Fell et autres sites de la région volcanique chilienne. Journal de la Société des Américanistes 52,169-255.

González-José, R. \& J. Charlin (2012). Relative Importance of Modularity and other Morphological Attributes on Different Types of Lithic Point Weapons: Assessing Functional variations. Plos ONE 10, 1-9.

Franco, N. V., A. Castro, M. Cardillo \& J. Charlin. (2009). La importancia de las variables morfológicas, métricas y de microdesgaste para evaluar las diferencias en diseños de puntas de proyectil bifaciales pedunculadas: un ejemplo del sur de Patagonia continental. Magallania 37(1),99-112.

Franco, N.V., J. Gómez Otero, G. Guráieb, M.S. Goye, N. Cirigliano \& A. Banegas. (2010). Variaciones espaciales en diseños de puntas pedunculadas medianas en Patagonia argentina: una nueva aproximación. En Actas del XVIII CNAA, Arqueología Argentina en el Bicentenario de la Revolución de Mayo. T.1:281286, FFyL (UNCu), INCIHUSA-CONICET, Mendoza.

Franklin, W. (1983). Contrasting socioecologies of South America's wild camelids: the vicuna and the guanaco. American Society of Mammalogy 7, 573-629.

Gallardo, C. (1910). Los Onas. Buenos Aires: Editorial Cabaut. Gómez Otero, J. (1987). Posición estratigráfica particular de puntas de los períodos IV y $\mathrm{V}$ de Bird en el alero Potrok-aike (Santa Cruz). En Comunicaciones de las Primeras Jornadas de Arqueología de la Patagonia, Gobierno de la Prov. del Chubut, Serie Humanidades 2,125-130

Gómez Otero, J. (1988). Investigaciones arqueológicas en el alero Potrok-aike (Provincia de Santa Cruz). Relaciones de la Sociedad Argentina de Antropología (N.S) XVII/I, 173-198.

Gómez Otero, J. (1989-90). Cazadores tardíos en la zona fronteriza argentino-chilena (paralelo $52^{\circ} \mathrm{S}$ ). El sitio Juni-Aike 1. Anales del Instituto de la Patagonia (Serie Ciencias Sociales) XIX, 47-71.

Gómez Otero, J. (1991). Discusión sobre el límite occidental del territorio de los proto-tehuelches y tehuelches meridionales en el extremo sud de Patagonia (cuenca del Río Gallegos). Waxen 6, 3-22.

Gómez Otero, J. (1994). The Function of Small Rockshelters in the Magallanes IV Phase settlement System. Latin American Antiquity 4(4), 325-345.

Gusinde, M. (1982). Los indios de Tierra del Fuego: los selk'nam, 2 Vol. Buenos Aires: CAEA-CONICET.

Iriarte, J. (1995). Afinando la puntería: tamaño, forma y rejuvenecimiento en las puntas de proyectil pedunculadas del Uruguay. In Actas del VIII Congreso Nacional de Arqueología Uruguaya, pp. 142-151. Montevideo, Uruguay.

Martínez J. (2003). Ocupaciones Humanas Tempranas y Tecnología de Caza en la Microrregión de Antofagasta de la Sierra (10000-7000 AP.). Tesis Doctoral, Universidad Nacional de Tucumán.

Massone, M. (1979). Panorama etnohistórico y arqueológico de la ocupación Tehuelche y Prototehuelche en la costa 
del Estrecho de Magallanes. Anales del Instituto de la Patagonia (Serie Ciencias Humanas) 10, 69-107.

Massone, M. (1981). Arqueología de la región volcánica Pali Aike (Patagonia Meridional Chilena). Anales del Instituto de la Patagonia (Serie Ciencias Sociales) XII, 125-140. Punta Arenas.

Massone, M. (1989-90). Investigaciones arqueológicas en la laguna Thomas Gould. Anales del Instituto de la Patagonia (Serie Ciencias Sociales) XIX, 87-99. Punta Arenas.

Massone, M. \& E. Hidalgo. (1981). Investigaciones arqueológicas en el alero Pali Aike 2 (Patagonia Meridional Chilena). Anales del Instituto de la Patagonia 12, 125 -140.

Molina, M. J. (1969-70). El Abrigo de los Pescadores (Prov. De Santa Cruz). Informe preliminar sobre un corte estratigráfico practicado en 1965. Anales de Arqueología y Etnología, Universidad de Nacional de Cuyo.

Morello, F.; M. San Roman \& A. Prieto (2004). Obsidiana verde en Fuego Patagonia: distribución y estrategias tecnológicas. En M. T Civalero; P. M. Fernández y A. Guraib (Eds.). Contra viento y marea. Arqueología de la Patagonia. Río Gallegos: Instituto Nacional de Antropología y Pensamiento.

Nami, H. (1984). Análisis tipológico de los instrumentos provenientes del sitio "El Volcán C4", cuenca del río Chico, Provincia de Santa Cruz. PREP-Informes de Investigación 1, 55-81.

Nami, H. (1999). Arqueología en la localidad arqueológica de Pali aike, cuenca del río Chico (Provincia de Santa Cruz, Argentina). Praehistoria 3, 189-201.

Nelson, M. (1991). The Study of Technological Organization. Archaeological Method and Theory, 3, 57-100.

Ortiz Troncoso, O. (1972). Material lítico de Patagonia austral. Seis yacimientos de superficie. Anales del Instituto de la Patagonia 3, 49-102.

Ortíz Troncoso, O. (1973). Aspectos arqueológicos de la península de Brunswick (Patagonia austral). Anales del Instituto de la Patagonia IV (1-3), 109-129.

Pisano, E. (1977). Fitogeografía de Fuego-Patagonia chilena I. Comunidades vegetales entre las latitudes $52^{\circ}$ y $56^{\circ}$ sur. Anales del Instituto de la Patagonia 8, 121-250.

Politis, G., L. Prates \& I. Perez (2009). El poblamiento de América. Arqueología y bioantropología de los primeros americanos. Colección Ciencia Joven No 35. Buenos Aires: EUDEBA.

Prieto Iglesias, A. (1989-90). Cazadores tardíos en la zona fronteriza del paralelo $52^{\circ}$ sur. II. Alero Peggy Bird. Anales del Instituto de la Patagonia (Serie Ciencias
Sociales) XIX, 73-85.

Prieto Iglesias, A. (1994). Arquería Selḱnam: La guerra y la paz en la Tierra del Fuego. Punta Arenas: Ed.Colegio Punta Arenas.

Puig, S. \& F. Videla (1995). Comportamiento y organización social del guanaco. En Técnicas para el Manejo del Guanaco, pp. 97-118. Gland: UICN.

Raedecke, K. (1978). El guanaco de Magallanes, Chile. Su distribución y biología. Ministerio de Agricultura de Chile, Corporación Nacional Forestal (CONAF), Chile, Publicación Técnica 4, 1- 182

Ratto, N. (1991). Análisis funcional de las puntas de proyectil líticas de sitios del sudeste de la Isla Grande de Tierra del Fuego. Arqueología 1, 151-178.

Ratto, N. (1993). What and how did they hunt? Methodological essay to approach the question of prehistoric hunting techniques. En J.L. Lanata (Ed.), Explotación de recursos faunísticos en sistemas adaptativos americanos. Buenos Aires: Arqueología contemporánea 4 (edición especial), pp. 135-148.

Ratto, N. (1994). Funcionalidad versus adscripción cultural: cabezales líticos de la margen norte del Estrecho de Magallanes. En J. L. Lanata y L. A Borrero (Eds.). Arqueología de Cazadores-Recolectores. Límites, Casos y Aperturas. Buenos Aires: Arqueología Contemporánea 5 (edición especial), pp. 105-120.

Ratto, N. (2003). Estrategias de caza y propiedades del registro arqueológico en la Puna de Chaschuil (Departamento Tinogasta, Catamarca). Tesis Doctoral, Universidad de Buenos Aires. Disponible en: http://cambiocultural.homestead.com/ratto.html.

Ratto, N. (2012). Diversidad de tecnología de caza en la Puna transicional de Chaschuil (Dpto. Tinogasta, Catamarca). Comechingonia 17 (1),83-101.

Ratto, N. \& B. Marconetto. (2012). Proyectiles en Acción, 20 Años Después.... Diseños en la fabricación de astiles fueguinos de colecciones etnográficas. En J. Martínez y D. Bozzuto (Eds.). Armas Prehispánicas, Múltiples Enfoques para su Estudio en Sudamérica, pp. 135-150. Buenos Aires: Ediciones FHN Félix de Azara.

Ratto, N \& O. Nestiero (1994). Ensayos Cuantitativos para la determinación de las propiedades físico mecánicas de las rocas: sus implicancias arqueológicas. En Actas y Memorias del XI Congreso Nacional de Arqueología Argentina (Resúmenes). Revista del Museo de Historia Natural de San Rafael. T. XIII (1-4), 368371, San Rafael, Mendoza.

Saba, S. (1987). Biología reproductiva del guanaco (Lama guanicoe Muller). Tesis Doctoral, Universidad Nacional 
de La Plata.

Sanguinetti de Bórmida, A.C. (1976). Excavaciones prehistóricas en la Cueva de las Buitreras, Santa Cruz. Relaciones de la Sociedad Argentina de Antropología (N.S.) X, 271-293.

Sanguinetti de Bórmida, A.C. \& L.A. Borrero. (1977). Los niveles con fauna extinta de la Cueva Las Buitreras (Río Gallegos, Provincia de Santa Cruz). Relaciones de la Sociedad Argentina de Antropología (N.S.) XI, 167175.

Scheinsohn, V. G., (1997). Explotación de materias primas óseas en la Isla Grande de Tierra del Fuego. Tesis Doctoral, Universidad de Buenos Aires.

Shott, M. (1993). Spears, Darts, and Arrows: Late Woodland Hunting Techniques in the Upper Ohio Valley.
American Antiquity 58 (3), 425-443.

Skewes, M. (1978). Geología, petrología, quimismo y origen de los volcanes del área de Pali-Aike, Magallanes, Chile. Anales del Instituto de la Patagonia 9, 95-106.

Stern, Ch. \& A. Prieto. (1991). Obsidiana verde de los sitios arqueológicos en los alrededores del mar de Otway, Magallanes, Chile. Anales del Instituto de la Patagonia, Serie Ciencias Humanas 20, 139-144.

Stern, Ch. \& N. Franco. (2000). Obsidiana gris verdosa veteada en la cuenca superior del río Santa Cruz, extremo sur de Patagonia. Anales del Instituto de la Patagonia, Serie Ciencias Humanas 28, 265-273.

Willey G.R. 1971. South America. An Introduction to American Archaeology. Vol. 2. New Jersey: PrenticeHall, Englewood Cliffs. 